\title{
The use of modelling and simulation approach in reconstructing past landscapes from fossil pollen data: a review and results from the POLLANDCAL network
}

\author{
Marie-José Gaillard · Shinya Sugita $\cdot$ M. Jane Bunting $\cdot$ Richard Middleton · Anna Broström $\cdot$ Christopher \\ Caseldine - Thomas Giesecke - Sophie E. V. Hellman - Sheila Hicks · Kari Hjelle · Catherine Langdon · \\ Anne-Birgitte Nielsen · Anneli Poska · Henrik von Stedingk · Sim Veski · POLLANDCAL members
}

Received: 15 November 2007 / Accepted: 11 June 2008/Published online: 1 August 2008

(C) Springer-Verlag 2008

\begin{abstract}
Information on past land cover in terms of absolute areas of different landscape units (forest, open land, pasture land, cultivated land, etc.) at local to regional scales is needed to test hypotheses and answer questions related to climate change (e.g. feedbacks effects of land-cover change), archaeological research, and nature conservancy (e.g. management strategy). The palaeoecological technique best suited to achieve quantitative reconstruction of past vegetation is pollen analysis. A simulation approach developed by Sugita (the computer model POLLSCAPE) which uses models based on the
\end{abstract}

Communicated by J. Dearing.

M.-J. Gaillard ( $₫)$ · S. E. V. Hellman

School of Pure and Applied Natural Sciences,

University of Kalmar, 39183 Kalmar, Sweden

e-mail: marie-jose.gaillard-lemdahl@hik.se

\section{S. Sugita}

Institute of Ecology, Tallinn University,

TLU, Uus-Sadama 5, 10120 Tallinn, Estonia

M. J. Bunting · R. Middleton

Department of Geography, University of Hull,

Cottingham Road, Hull HU6 7RX, UK

\section{A. Broström}

Geobiosphere Science Centre, Lund University,

Sölvegatan 12, 22362 Lund, Sweden

C. Caseldine $\cdot$ C. Langdon

School of Geography, Archaeology and Earth Resources, University of Exeter, Cornwall Campus, Treliever Road,

Penryn, Cornwall TR11 9EZ, UK

T. Giesecke

Department of Geography, University of Liverpool,

Roxby Building, Liverpool L69 7ZT, UK theory of pollen analysis is presented together with examples of application. POLLSCAPE has been adopted as the central tool for POLLANDCAL (POLlen/LANdscape CALibration), an international research network focusing on this topic. The theory behind models of the pollen-vegetation relationship and POLLSCAPE is reviewed. The two model outputs which receive greatest attention in this paper are the relevant source area of pollen (RSAP) and pollen loading in mires and lakes. Six examples of application of POLLSCAPE are presented, each of which explores a possible use of the POLLANDCAL tools and a means of validating or evaluating the models with empirical data. The landscape and

S. Hicks

Department of Geography, University of Oulu,

P.O. Box 3000, 90014 Oulu, Finland

K. Hjelle

Natural History Collections, University of Bergen,

5007 Bergen, Norway

\section{A.-B. Nielsen}

Department of Quaternary Geology,

Geological Survey of Greenland and Denmark,

$\varnothing$. Voldgade 10, 1350 Copenhagen, Denmark

\section{A. Poska - S. Veski}

Institute of Geology, Tallinn University of Technology,

Ehitajate tee 5, 19086 Tallinn, Estonia

H. von Stedingk

Department of Forest Ecology and Management,

Swedish University of Agricultural Sciences,

90183 Umeå, Sweden 
vegetation factors influencing the size of the RSAP, the importance of pollen productivity estimates (PPEs) for the model outputs, the detection of small and rare patches of plant taxa in pollen records, and quantitative reconstructions of past vegetation and landscapes are discussed on the basis of these examples. The simulation approach is seen to be useful both for exploring different vegetation/ landscape scenarios and for refuting hypotheses.

Keywords POLLANDCAL network POLLSCAPE simulation model .

Pollen dispersal and deposition .

Relevant source area of pollen .

Quantitative reconstructions of past vegetation and landscapes

\section{Introduction}

The aim of this paper is to demonstrate the utility of and need for the modeling and simulation approach as implemented by POLLSCAPE (Sugita 1994), and to illustrate the potentials of modeling with examples of applications produced by the NordForsk (Nordic Research Council, formely NorFA) research-network POLLANDCAL (POLlen-LANDscape CALibration).

Pollen-analysis is one of the most commonly used palaeoecological tools for reconstructing past landscapes. The qualitative characteristics of the landscape are generally inferred from pollen percentage data, using the indicator species approach (Iversen 1944, 1964). Alternatively, but less frequently, pollen accumulation rates (PARs, often referred to as pollen influx data) are used to obtain an independent index of the representation of plant taxa in the vegetation (e.g. Davis 1966, 1968; Hicks and Hyvärinen 1999) and have been applied in delimiting the local presence/absence and abundance of selected tree species in north-west Europe (e.g. Hicks 2001). However, PARs are more often combined with percentage data to assess whether changes in pollen percentages are genuine or a product of the percentage calculation (e.g. Gaillard 1985; Gaillard and Lemdahl 1994; Snowball et al. 2001). The precise quantitative reconstruction of past plant abundance from fossil pollen records has been a primary focus for many palynologists ever since the initiation of the pollen-analysis technique, although it has also proved to be problematical (e.g. Sugita 1994). To solve several of the important questions posed within climate change research, archaeology and ecology/landscape management, there is a need to reconstruct landscapes in terms of spatially defined forests, open land, pastures, cultivated fields, etc. (e.g. Gaillard et al. 2000; Anderson et al. 2006; Gaillard 2007).
In an attempt at achieving quantitative reconstruction from fossil pollen data, a few palynologists have produced models of the pollen/vegetation relationship (Davis 1963; Andersen 1970; Parsons and Prentice 1981; Prentice and Parsons 1983; Prentice 1985). Because of the limitations of their application (Davis 1963; Andersen 1973) or the complexity of their theory (Prentice 1985), these models have been largely neglected or very little used by palynologists. The "correction factors" of Andersen (1970, 1973), one output of such models, have been used more widely for vegetation reconstructions from fossil pollen but, unfortunately, also often misused. Sugita $(1993,1994)$ has taken the modeling approach a step further by developing the mechanistic model proposed by Prentice (1985), clearly defining the pollen source area concept and proposing a simple simulation approach, "POLLSCAPE", that all palynologists can potentially use in their interpretation procedure. Moreover, within the POLLANDCAL activities, Sugita $(2007 \mathrm{a}, \mathrm{b})$ developed the landscape reconstruction algorithm (LRA), a research strategy that combines modeling and a simulation approach in order to reconstruct vegetation quantitatively at both local and regional spatial scales using pollen data from small and large basins (lakes or bogs). The LRA includes two models, Regional Estimates of VEgetation Abundance from Large Sites (REVEALS) and LOcal Vegetation Estimates (LOVE). REVEALS quantitatively estimates vegetation (in proportions of cover) in a region $\left(\geq 10^{4} \mathrm{~km}^{2}\right)$ from fossil pollen samples in large lakes ( $\geq 100$ ha). LOVE estimates the local vegetation abundance within the RSAP using fossil assemblages from small sites $(<100$ ha) and REVEALS estimates of the regional vegetation. REVEALS was validated and tested in southern Sweden (Anderson et al. 2006; Hellman et al. 2008a, b, this volume; Sugita et al. 2008, in press), and central Europe (Soepboer et al. 2008, in press). The validation of LOVE, as well as applications of REVEALS and LOVE in various parts of Europe are under progress. In this paper we do not deal with LRA, REVEALS and LOVE, but focus essentially on the utility of the simulation approach POLLSCAPE for vegetation reconstructions inferred from pollen records.

\section{The POLLANDCAL network}

POLLANDCAL is a research network that was supported by NordForsk for 5 years (2001-2005) and still is active ( http://www.ecrc.ucl.ac.uk/pollandcal). It was launched in February 2001 and adopted the approach of Sugita (1994) as a working framework to achieve the goal of quantitative landscape reconstruction, with the aims of developing the approach, training a group of palynologists in its application, and reaching the larger international community. The 
network includes research groups from 14 countries (Sweden, Norway, Finland, Denmark, Iceland, Estonia, Poland, UK, Germany, Switzerland, France, The Netherlands, Japan and USA) (Appendix). The long-term aim of the network was to achieve a robust calibration tool for quantitative reconstruction of past landscapes using fossil pollen assemblages, and had two major foci: (1) the collection of empirical data on modern pollen-vegetation relationships, and (2) the use and development of models and computer software. Within the first focus, syntheses of published data were made, methodologies were standardized, new data were collected, and collaboration was developed to extend datasets across Europe (Broström et al. 2004; Bunting et al. 2005; von Stedingk 2006; von Stedingk et al. 2008, in press; Mazier et al. 2008, this volume; Soepboer et al. 2007a, b, this volume; Broström et al. 2008, this volume). Within the second focus, the network members were trained in the use of the POLLSCAPE model. Moreover, user-friendly, highly flexible software was produced (Middleton and Bunting 2004; Bunting and Middleton 2005) and alternative algorithms for pollen dispersal and deposition were developed and tested, which lead to the HUMPOL computer programme suite (Bunting and Middleton 2005). Finally, the simulation approach was used in hypothesis testing, the design of research projects, and in the interpretation of pollen data (Broström et al. 2005; Nielsen 2003, 2004; Nielsen and Sugita 2005; Bunting et al. 2004; Fyfe 2006; Caseldine and Fyfe 2006; Caseldine et al. 2007a, b). Besides the development of the LRA (Sugita 2007a, b; see above), Bunting et al. (2007, 2008) developed the "multiple scenario approach" (MSA), which uses a combination of GIS techniques, pollen dispersal and deposition modelling and analogue matching statistical approaches to reconstruct likely past landscape scenarios from fossil pollen assemblages. Progress made by the network and information on its various activities is published on its web-site.

Today, thanks to the LRA and MSA, we are able to reconstruct past vegetation quantitatively, both as percentage cover in a specified area (regional vegetation: $\geq 50 \mathrm{~km} \times 50 \mathrm{~km}$; or local vegetation: RSAP of small lakes or bogs), given pollen productivity estimates (PPEs) are available for the study area. The network members are still collaborating in a number of new research projects with the aim of collecting more empirical data to obtain PPEs for the major taxa of the most important vegetation types of the world, and to validate and apply the LRA and MSA for vegetation/landscape quantitative reconstruction. The network is now involved in the IGBP-PAGES-Focus 4 activity in which reconstruction of land-cover at the continental to global scale for the purpose of global climate and environmental research is a primary goal.
Theoretical basis for pollen analysis and quantitative reconstruction of past vegetation: a review

Jackson and Kearsley (1998) and Jackson and Lyford (1999) have produced reviews of the pollen dispersal models used in quantitative reconstructions of past vegetation, and made a thorough analysis of the assumptions and parameters involved. Moreover, the key steps and basic assumptions underlying the theory of the POLLSCAPE model are described in several earlier papers by Bunting et al. (2004, 2005), Broström et al. (2004, 2005, 2008), Nielsen (2003), Sugita (2007a, b), Hellman (2007) and Hellman et al. (2008a, b, this volume). Here, we aim at summarizing and updating these descriptions in a single review.

The pollen-vegetation relationship and ERV models

Many factors are influencing pollen assemblages in lake and bog deposits and their representation of vegetation. Parameters of importance are pollen productivity of the source plants, and dispersal and deposition properties of the pollen, both differing between taxa (Sugita 1993; Broström 2002; Nielsen 2003). The historical and theoretical background of the models of the pollen-vegetation relationship, and of the Extended $R$-Value (ERV) models in particular, is carefully described by Jackson (1994), Sugita (1993, 2007a, b), Broström (2002), Nielsen (2003) and Hellman (2007).

The origin of the models we are using today is Margaret Davis's $R$-value model (Davis 1963). The $R$-value model was designed to convert pollen percentages into relative tree abundances (Davis 1963). However, the main practical problem with the $R$-value model is the spatial scale for specification of the plant abundance, i.e. the size of the vegetation area from which to extract plant data. The input of pollen from outside the surveyed area (i.e. the background pollen), if ignored, may have significant effects on the estimation of $R$ values (Parsons and Prentice 1981). It is precisely this "background" pollen component that the $R$ value model did not take into account, and the reason why the model failed in its more general use. Because the background pollen component varies between regions, and with the size of the surveyed area, the $R$ values will also vary between regions. The difficulties encountered with $R$ values, both in theory and practice, resulted in very critical and pessimistic views from many palaeoecologists in the 1960s and 1970s.

Andersen (1970) proposed a model that included a background pollen component. But this model only applies to absolute pollen loading, or some variable proportional to this, such as PAR (pollen per unit volume of sediment and unit of time). However, PAR may be difficult to obtain (as it implies a detailed and reliable chronology for the pollen 
record), and has been demonstrated to be highly variable between lakes and even within a single lake (e.g. Davis et al. 1973, 1984). This explains why pollen analysts still mainly use pollen percentages, either alone or in combination with pollen concentrations (pollen per unit volume of sediment) and/or PAR.

Linear regression can be applied to pollen and vegetation percentage data only if there are no dominant taxa in the vegetation, which is seldom the case. There is the "theoretical expectation of non-linearity" of the relationship between pollen and vegetation expressed in percentages (Fagerlind 1952). This implies that the linear relationship becomes non-linear when absolute measured variables (such as pollen counts) are converted to percentages. The Fagerlind effect has to be corrected in order to improve the goodness-of-fit between pollen and vegetation data. The ERV-model was developed for percentage pollen and vegetation data, and expresses the pollen-vegetation relationship as a linear regression with its slope being the pollen productivity and its intercept the background pollen component (Parsons and Prentice 1981; Prentice and Parsons 1983). Furthermore, it is important to capture the "pollen sample's view of the vegetation" when modelling the pollen-vegetation relationship (Webb et al. 1981). Therefore, distance weighting of plant abundance should be applied in ERV-models. Distance weighting corrects for the fact that plants close to the sampling site contribute more pollen than plants situated further away. Unweighted plant abundance has also been applied (Bradshaw and Webb 1985; Prentice et al. 1987; Jackson 1990), but this only reflects the "pollen sample's view" if all pollen released from the vegetation within the area analysed is distributed evenly (Jackson and Kearsley 1998). The simplest way to weight the vegetation is by dividing the plant abundance by the distance $d$ between the plant and the point where pollen is deposited (pollen sample), 1/d (Prentice and Webb 1986), or by the square of the distance, $1 / d^{2}$ (Webb et al. 1981; Schwarz 1989; Calcote 1995; Jackson and Kearsley 1998). A more sophisticated method, the taxon-specific distance weighting, takes into account the dispersal ability of the pollen grain of each taxon, based on the size, form and density of the grain (Prentice 1985; Sugita 1993). Calcote (1995) demonstrated that $1 / d^{2}$ is a good approximation of the taxon-specific distance weighting in the case of forested vegetation in Northern USA. Broström et al. (2004) suggested that the taxon-specific distance weighting is the best to use when applying ERV-models to calculate estimates of pollen productivity and background pollen in the case of the cultural landscapes of southern Sweden.

ERV-sub-model 1 was introduced by Parsons and Prentice (1981). It assumes that the background pollen loading for each taxon $i$ is a constant proportion of the total pollen loading. Prentice and Parsons (1983) proposed a second sub-model that assumes that the background pollen loading for each taxon $i$ is a constant proportion of the total plant abundance. Finally, Sugita (1994) proposed a third submodel that can be used if absolute vegetation abundance is known. The three sub-models should give very similar results if the background pollen loading is low compared to the total pollen loading (Jackson and Kearsley 1998). Large differences in pollen productivity among taxa and/or in vegetation composition among sites may lead to less good estimates from sub-model 1, whereas large differences in total plant abundance among sites may result in less good estimates from sub-model 2 (Prentice and Parsons 1983). The values of the background pollen and the relative values of the pollen productivity can be estimated from a dataset of pollen proportions and vegetation proportions (or abundances for sub-model 3) from a sufficient number of sites within a given region using maximum likelihood methods as described by Parsons and Prentice (1981), Prentice and Parsons (1983) and Sugita (1994).

The Prentice model of pollen dispersal and deposition is appropriate for describing the pollen-vegetation relationship using pollen records from bogs and mires, where the horizontal movement of pollen after deposition is negligible. Because mixing and focusing redistribute the pollen originally deposited on a lake (Davis and Brubacker 1973; Davis et al. 1984), Sugita (1993) modified the Prentice model to estimate pollen deposition over the entire surface of a basin. Sugita's model provides a reasonable approximation of the pollen-vegetation relationship for pollen records from lakes and ponds. Hereafter, the models developed by Prentice and Sugita will be called "the Prentice-Sugita model", because their functional structure is similar, and their parameterization of factors and mechanisms are only slightly different.

The basic assumptions for the Prentice-Sugita model are as follows:

1. The sampling basin is a circular opening in the canopy

2. Pollen dispersal is even in all directions

3. The dominant components of pollen transport are the wind component above the canopy and the gravity component beneath the canopy

4. Pollen productivity is constant for each taxon

5. Spatial distribution of each taxon is expressed as a function of distance from the centre of the depositional basin

6. The crosswind-integrated deposition of pollen is approximated by a function of distance from a plant (i.e. point source) derived from a diffusion model of small particles from a ground-level source (Sutton 1953).

Some of these assumptions are often violated in the real world; most natural basins are not circular, some wind 
directions are prevailing, and pollen grains are not transported only by wind (Nielsen 2003; Hellman et al. 2008b, this volume). Moreover, in half-open mosaic landscapes, the height of the canopy varies from low in herbaceous vegetation to high in forested areas, and landscape topography affects wind patterns and pollen transport, especially in mountainous regions.

The two models of Prentice and Sugita may be regarded as end members of various situations, from no mixing of pollen in the water column (Prentice 1985) to complete mixing (Sugita 1993). Because models are always a simplification of the real world, they should be tested and validated against empirical data before they can be used. The Prentice-Sugita model was validated within forested vegetation of northern America (Calcote 1995; Sugita et al. 1997), mosaic cultural landscapes of southern Scandinavia (Sugita et al. 1999; Nielsen 2004), and the Swiss Plateau (Soepboer et al. 2008, in press).

The pollen dispersal-deposition function used in the Prentice-Sugita model defines how a given abundance of plants at a certain distance is registered in pollen records. As already explained above, the same number of plants $5 \mathrm{~m}$, for example, away from the study sites provides more pollen grains to the site than the same number of plants $1,000 \mathrm{~m}$ away. In addition, as the distance from a sedimentary basin increases, the number of plants that contribute pollen to a site also increases. The PrenticeSugita model is a simple mathematical description expressing both phenomena (Sugita 1994, 1998, 2007c). Sugita proposed two additional models for pollen dispersaldeposition on lakes and ponds that improve the accuracy of the pollen-loading calculation, the Finite Line Source model (FLS model) (Sugita et al. 1997) and the Ring Source model (RS model) (Sugita et al. 1999). In the FLS model, the plant source is expressed as a line (or a line in the form of the circumference of a circle) the length of which is a function of the distance from the basin. In the RS model, the plant source is expressed as a succession of concentric rings around the pollen site, and pollen loading is obtained by integrating ERV model calculations over these concentric rings from the pollen sampling point (bog) or the lake shore out to the largest distance of the vegetation survey. The RS model has been implemented as the kernel of pollen dispersal-deposition in the most recent simulation studies using the Prentice-Sugita model (e.g. Sugita et al. 1999; Nielsen 2003, 2004; Nielsen and Sugita 2005; Soepboer et al. 2007b; Sugita 2007b; this paper).

The deposition velocity of the pollen type has to be known if pollen dispersal-deposition models are to be used. It is assumed to be equivalent to the terminal velocity or fall speed of pollen (Prentice 1985). It has been measured for a number of pollen types (Eisenhut 1961) or calculated according to Stoke's law (Gregory 1973; Sugita et al. 1999;
Broström et al. 2004; Mazier et al. 2008, this volume). The model assumes neutral atmospheric conditions, which means that the turbulence parameter and the vertical diffusion coefficient are constant values (Prentice 1985). This assumption has been discussed and criticized by Jackson and Lyford (1999), as unstable atmospheric conditions should be more typical than neutral conditions during the periods when most pollen is released. This question is further explored by simulations and discussed in this paper (Sugita, see below).

The pollen source area: "characteristic radius" versus "relevant source area of pollen"

Because pollen grains can potentially be carried by wind many metres or kilometres, it is difficult to define the spatial scale of the source area for pollen in sediment. However, ecological phenomena are scale-dependent. Unless the spatial scale is clearly defined, pollen-based reconstructions and interpretation of past vegetation and landscape dynamics will not make sense ecologically (Davis 2000). If vegetation is homogeneous, the spatial scale of the pollen source can be calculated as a "characteristic radius" (CR) from which a certain fraction of pollen of a given taxon comes, for example 60 or $70 \%$ (Prentice 1988; Sugita 1993). This concept is useful to generalize the effects of differences in basin size and intertaxonomic differences in pollen dispersal characteristics on the source area of pollen or the spatial scale of vegetation represented by pollen records. Theoretical predictions of the CR agree with empirical observations in general (Prentice 1988; Sugita 1993), i.e. (1) the larger the basin size, the larger the CR, and (2) the more well-dispersed the pollen type, the larger the CR. However, vegetation is generally heterogeneous. To take account of the heterogeneity, Sugita $(1994,1998)$ proposed the concept of the "relevant source area of pollen" (RSAP), which is defined as the area beyond which correlation between pollen loading in a sedimentary basin and vegetation abundance for all taxa in the landscape does not continue to improve, even with continued sampling to greater distances. Pollen loading coming from beyond the RSAP (i.e. the "background pollen") is similar at all sites of similar size. This means that differences in pollen loading among similarly sized sites represent differences in plant abundance within the RSAP at individual sites, superimposed on a constant background pollen component (Sugita 1994, 1998, 2007b). The RSAP can be estimated using the ERV-model (see above) and the maximum likelihood method (Parsons and Prentice 1981; Prentice and Parsons 1983; Sugita 1994; Broström et al. 2005). The "likelihood function score" (or, more precisely, the negative value of the support function for the multinomial distribution function (sensu Edwards 
1972)) for the corrected pollen-vegetation relationship for all taxa over distance from the sampling point is calculated using the ERV-models (see above). The RSAP is defined as the distance at which the likelihood function scores reach an asymptote (Sugita 1994; see also application example 1 below). There was no standard method for identifying the distance at which this occurs at the time of the studies presented below. Therefore, we used visual identification from a plot of likelihood function scores against distance (e.g. Sugita et al. 1999; Broström et al. 2005). Because this method is subjective, a quantitative approach to identify the position of the RSAP, the "moving-window linear regression method" was proposed by Sugita (this paper) and applied by Sugita (2007b) and Hellman et al. (2008c, $2008 \mathrm{~d}$, in press). The method is described in detail below.

The RSAP has been quantified empirically in northern Michigan (Calcote 1995), southern Sweden (Broström et al. 2005), central Sweden (von Stedingk 2006), Denmark (Nielsen and Sugita 2005), Switzerland (Soepboer et al. 2007a; Mazier et al. 2008, this volume), and England (Bunting et al. 2005).

Computer simulation models: POLLSCAPE and its successor HUMPOL

The POLLSCAPE (Sugita 1994) and HUMPOL (Bunting and Middleton 2005) computer simulation models allow the calculation of pollen dispersal and deposition in heterogeneous landscapes, and the estimation of pollen assemblages in lakes or bogs of given sizes. HUMPOL may be described as a form of POLLSCAPE with greater flexibility, applying a pixel-based rather than a ring-based approach (see the RS model above, Sugita et al. 1999) and other algorithms to extract vegetation data. The two computer simulation models include Sugita's (1993) and Prentice's (1985, 1988) model options to express pollen dispersal and deposition. They use PPEs and data on the abundance and spatial distribution of plant species from simulated hypothetical landscapes (e.g. Sugita 1994; Davis and Sugita 1996; Sugita et al. 1999, Bunting et al. 2004; Bunting and Middleton 2005) or from real landscapes (such as satellite images or vegetation and inventory maps, e.g. Broström et al. 2005; Mazier 2006; Sugita et al. 1997; Nielsen 2004). The simulation process has four stages, (1) landscape design (simulation or extraction from mapped data), (2) extraction of sample-specific vegetation data relative to chosen locations, (3) simulation of pollen loading at each location and (4) the estimation of RSAP by comparing pollen and vegetation data for each location using ERV-models (see above). The various computer programmes used to achieve each stage are as follows. Stage 1 is carried out using OPENLAND 2 (POLLSCAPE; Sugita et al. 1999) or MOSAIC (Middleton and Bunting 2004) to create hypothetical maps of vegetation distribution; MOSAIC is a user-friendly alternative to OPENLAND 2 and is more commonly used within the POLLANDCAL network today. PolGRID (HUMPOL utility; Middleton, unpublished) can translate grids produced in commercial GIS packages such as ArcView into the format required by POLLSCAPE and HUMPOL. In POLLSCAPE Stage 2 is carried out by OPENLAND 3 (Eklöf et al. 2004), which extracts the vegetation data relative to each sample point in the format needed by POLSIM v3 (Sugita, unpublished). The latter implements stages 3 and 4 by simulating pollen loading at each point using the dispersal and deposition models and carrying out ERV analysis. The program output comprises modelled pollen counts, likelihood function scores (for estimation of RSAP) and estimates of PPE and background component. ERV-v6 is a new version of the programme written by Sugita (1994) to implement ERV-models. HUMPOL organizes these stages differently. PolFLOW (Bunting and Middleton 2005) extracts vegetation data and simulates pollen loadings at sample points using the dispersal and deposition models, and produces an output file which includes the input data needed for ERV analysis. Using PolLOG (HUMPOL utility; Middleton, unpublished) these data can then be extracted from the output file in one of two formats, either for use in ERV-v6 (Sugita 1994) or for use in the utility PolERV (HUMPOL utility; Middleton, unpublished) which is a user-friendly 'shell' around Sugita's ERV-v6 code for ERV analysis.

POLLSCAPE was originally created to simulate pollen dispersal and deposition in a closed forest system, assuming that the dominant agent of pollen transport is wind just above the canopy. It has been successful in predicting the RSAP and pollen assemblages in relatively simple, closed forest systems in USA and Canada (Sugita 1994, 1998; Calcote 1995; Sugita et al. 1997). POLLSCAPE has also been shown to function well for simulations using pollen data from small lakes in the modern cultural landscapes of southern Sweden (Sugita et al. 1999; Broström et al. 2005) and the historical A.D. 1850 landscapes of Denmark (Nielsen 2004). However, although POLLSCAPE was capable of predicting pollen assemblages in this type of vegetation using simulated landscapes, the model does not incorporate differences in source height of pollen between trees and herbaceous plants, differences in air movement and turbulence in landscapes with various degrees of openness, and differences in surface roughness between forests and open vegetation. These potential problems have been emphasized by the authors. There is an obvious need to proceed with further validation using "real-world" landscapes.

Simulation experiments using POLLSCAPE or HUMPOL have provided useful insights on the pollen representation of vegetation in large and small lakes (Sugita 1994; Sugita et al. 1999; Bunting et al. 2004; Broström 
et al. 2005; Hellman et al. 2008c, d, in press). In this paper, we present applications of POLLSCAPE only, as this work was achieved at a time when the development of HUMPOL still was in progress.

\section{Examples of applications}

The following examples show ways in which members of the POLLANDCAL group have used different components of POLLSCAPE to address questions of relevance to their own research. Together they serve to illustrate a few of the vast range of possibilities that exist. These studies were performed during the sponsored period of the POLLANDCAL NordForsk network, 2001-2005.

General methods

Table 1 summarizes the major materials, methods and parameters used in the examples of applications presented in this paper. When nothing else is specified below, MOSAIC is used for the landscape simulations, OPENLAND3 to calculate the distance-weighted plant abundances, and pollen loadings were simulated in POLSIM ve3 using the RS model (Sugita et al. 1999) (examples 1-3) or the Prentice model (Prentice and Parsons 1983) (examples 4-6) on distance-weighted vegetation data, assuming the same mean plant abundances beyond the borders of the landscape as within the landscape. Pollen sums of 1,000 grains were simulated. Sub-model 3 of the ERV model (Sugita 1994) was applied to estimate the RSAP. The RSAP was then estimated by plotting likelihood function scores derived from the ERV model against distance from the basin edge, and identifying the asymptote.

Table 1 Type of vegetation data, PPEs and models used in the six examples of application of POLLSCAPE presented and discussed in this paper

\begin{tabular}{|c|c|c|c|c|c|c|}
\hline \multirow[t]{2}{*}{ Choices } & \multicolumn{6}{|c|}{ Example no } \\
\hline & 1 & 2 & 3 & 4 & 5 & 6 \\
\hline Simulated vegetation & $X$ & & & $\mathrm{X}$ & $\mathrm{X}$ & $\mathrm{X}$ \\
\hline Actual vegetation & & & $X$ & & & $\mathrm{X}$ \\
\hline Calculated pollen loading & $\mathrm{X}$ & $\mathrm{X}$ & $\mathrm{X}$ & $\mathrm{X}$ & $\mathrm{X}$ & $\mathrm{X}$ \\
\hline Calculated RSAP & $\mathrm{X}$ & $\mathrm{X}$ & $X$ & & & \\
\hline $\begin{array}{l}\text { PPE from southern Sweden (Broström et al. } \\
\text { 2004) }\end{array}$ & & $\mathrm{X}$ & $\mathrm{X}$ & $\mathrm{X}$ & $\mathrm{X}$ & $\mathrm{X}$ \\
\hline PPE from Norway (Hjelle 1998) & & & & & $\mathrm{X}$ & \\
\hline $\begin{array}{l}\text { PPE from Wisconsin and Michigan (Sugita } \\
\text { 1994) }\end{array}$ & $\mathrm{X}$ & & & & & \\
\hline Prentice's model (for bogs) & & & & $\mathrm{X}$ & $\mathrm{X}$ & $\mathrm{X}$ \\
\hline Sugita's model (for lakes) & $\mathrm{X}$ & $\mathrm{X}$ & $\mathrm{X}$ & & & \\
\hline
\end{tabular}

Table 2 Pollen productivity estimates (PPEs) and fall speed of pollen for 26 NW European plant taxa (from Broström et al. 2004; trees from Sugita et al. 1999, converted to Poaceae =1)

\begin{tabular}{|c|c|c|}
\hline Pollen taxa & Fall speed & PPE \\
\hline Acer spp. & 0.056 & 1.27 \\
\hline Alnus glutinosa & 0.021 & 4.23 \\
\hline Betula spp. & 0.024 & 8.94 \\
\hline Calluna vulgaris & 0.038 & 4.7 \\
\hline Carpinus betulus & 0.042 & 2.56 \\
\hline Cerealia & 0.06 & 3.2 \\
\hline Comp. SF Cichorioideae & 0.051 & 0.24 \\
\hline Corylus avellana & 0.025 & 1.42 \\
\hline Cyperaceae & 0.035 & 1 \\
\hline Fagus sylvatica & 0.057 & 6.73 \\
\hline Filipendula ulmaria & 0.006 & 2.48 \\
\hline Fraxinus excelsior & 0.022 & 0.67 \\
\hline Juniperus communis & 0.016 & 2.08 \\
\hline Picea abies & 0.056 & 1.77 \\
\hline Pinus sylvestris & 0.031 & 5.71 \\
\hline Plantago lanceolata SE & 0.029 & 12.76 \\
\hline Poaceae & 0.035 & 1 \\
\hline Potentilla type & 0.018 & 2.47 \\
\hline Quercus spp. & 0.035 & 7.60 \\
\hline Ranunculus acris type & 0.014 & 3.85 \\
\hline Rubiaceae & 0.019 & 3.95 \\
\hline Rumex acetosa type & 0.018 & 4.7 \\
\hline Salix spp. & 0.022 & 1.27 \\
\hline Secale cereale & 0.06 & 3.04 \\
\hline Tilia cordata & 0.032 & 0.8 \\
\hline Ulmus glabra & 0.032 & 1.27 \\
\hline
\end{tabular}

SE and PPEs were estimated on the basis of vegetation and pollen data collected in ancient cultural landscapes of southern Sweden

Atmospheric parameters follow Sugita et al. (1999) and wind speed is generally set to $3.0 \mathrm{~m} \mathrm{~s}^{-1}$, following Tauber (1965), Prentice (1985), Sugita (1994), Sugita et al. (1999) and Broström et al. (2004, 2005). Values for PPEs and fall speed of pollen are from Broström et al. (2004; Table 2) except in two cases (S. Sugita and K. Hjelle, see below).

Testing model hypotheses and theoretical concepts

Effects of the atmospheric conditions on distance weighting and on the RSAP (Shinya Sugita)

When plant abundance is properly distance-weighted for individual taxa, the pollen-vegetation relationship is linear, and the slope represents the pollen productivity (Prentice 1985; Sugita 1994; Sugita et al. 1997, 1999) (see theoretical background above). For the purpose of distance-weighting, a neutral condition of the atmosphere 
is generally assumed. Jackson and Lyford (1999) raised a question on the validity of this assumption, particularly when pollen dispersal models are applied to estimate the spatial scale of vegetation represented by pollen. Therefore, simulations were designed to show:

1. How the differences in the atmospheric conditions affect the RSAP

2. How sensitive the pollen dispersal function under the neutral condition could be as a method to distanceweight plant abundance and quantify the pollenvegetation relationship in a heterogeneous landscape under different atmospheric conditions.

Methods: Simulation design for the spatial pattern of vegetation: The OPENLAND2 programme was used to create a $60 \mathrm{~km} \times 60 \mathrm{~km}$ plot, in which circular patches of three stand types are randomly distributed in the matrix dominated by hemlock (Tsuga sp.). The three patch types and the matrix have specific species composition (Table 3). Patch type 1 is dominated by maple (Acer sp.), patch type 2 co-dominated by hemlock and pine (Pinus sp.), and patch type 3 by birch (Betula sp.). In each patch and the matrix, the vegetation is assumed to be homogeneous. Patch size varies, and the mean size for patch types 1,2 and 3 is 15.0 ha $(\mathrm{SD}=5.0 \mathrm{ha}), 5.0$ ha $(\mathrm{SD}=4.0 \mathrm{ha})$ and 2.0 ha $(\mathrm{SD}=1.0 \mathrm{ha})$, respectively. The overall proportions of the area covered by the matrix and patch types 1, 2 and 3 are $0.40,0.30,0.20$ and 0.10 , respectively (Table 3; Fig. 1).

Pollen loadings and assemblages on a lake of radius $50 \mathrm{~m}$ were calculated. The location of the lake was randomly selected in the central portion of the plot, at least $25 \mathrm{~km}$ away from the edge of the plot. The same procedure was repeated 30 times to simulate pollen assemblages at 30 lakes. Pollen productivity and fall speed of pollen for individual taxa are listed in Table 4. The pollen productivity of hemlock was fixed at 1.0 and

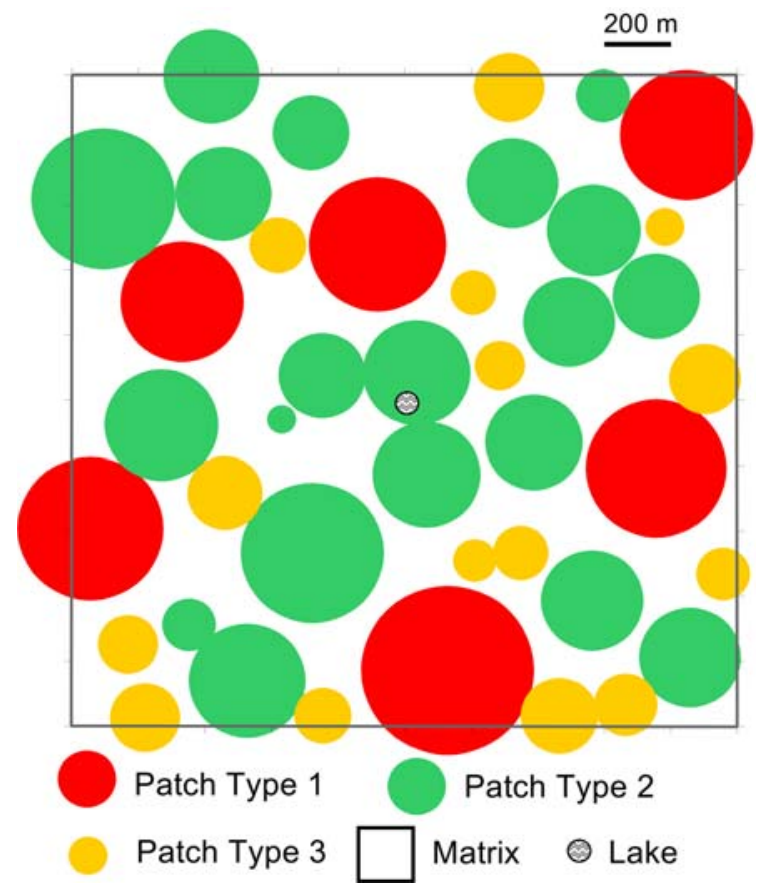

Fig. 1 Landscape design to simulate pollen deposition on lakes in example no. 1. Three types of vegetation patches are randomly distributed in the matrix of a Tsuga sp.-dominated stand. Each stand type has a distinctive species composition as specified in Table 3. The simulations assume that species composition in each patch and the matrix is homogeneous in space. The simulated plot is $60 \mathrm{~km} \times 60 \mathrm{~km}$. A lake $50 \mathrm{~m}$ in radius is placed randomly in the central portion of the plot, and pollen loading and assemblages of the five taxa (Tables 3, 4) are calculated using the Ring-Source Model (Sugita et al. 1999). In total, 30 lakes are simulated independently to estimate the relevant source area of pollen (sensu Sugita 1994) in this landscape

those of other taxa were adjusted accordingly. Pollen coming from beyond the plot out to $400 \mathrm{~km}$ was calculated as a regional component. Plant abundance of individual taxa was estimated at every $5 \mathrm{~m}$ from the lakes out to $1,500 \mathrm{~m}$.

Table 3 Spatial vegetation structure in the landscape and the species composition used for the simulation to compare the RSAP when atmospheric condition varies

\begin{tabular}{llllll}
\hline & Matrix & Patch type 1 & Patch type 2 & Patch type 3 & Overall abundance \\
\hline Overall proportion in the region & 0.40 & 0.30 & $15 \pm 5$ & 0.20 & 0.10 \\
Mean size (ha) & & 0.01 & 0.45 & $2 \pm 1$ & 0.30 \\
Tsuga sp. & 0.80 & 0.75 & 0.01 & 0.15 & 0.443 \\
Acer sp. & 0.01 & 0.03 & 0.05 & 0.50 & 0.246 \\
Betula sp. & 0.13 & 0.20 & 0.04 & 0.04 & 0.121 \\
Tilia sp. & 0.01 & 0.01 & 0.45 & 0.01 & 0.114 \\
Pinus sp. & 0.05 & &
\end{tabular}

The landscape consists of four stand types (the matrix and three patch types). Each stand type has a distinctive stand composition. The spatial distribution of the constituent taxa is assumed to be homogeneous in each stand type 
Table 4 PPEs and fall speed for each taxon used in the simulation, from Sugita (1994) and Calcote (1995)

\begin{tabular}{lll}
\hline & Pollen productivity & Fall speed of pollen $\left(\mathrm{m} \mathrm{s}^{-1}\right)$ \\
\hline Tsuga sp. & 1.000 & 0.056 \\
Acer sp. & 0.327 & 0.056 \\
Betula sp. & 2.775 & 0.024 \\
Tilia sp. & 0.181 & 0.032 \\
Pinus sp. & 1.078 & 0.031 \\
\hline
\end{tabular}

Atmospheric conditions: The parameters representing the neutral and unstable conditions of the atmosphere required in Sutton's dispersal model are as presented in Table 5. The parameter values for the neutral condition are from Sutton (1953), and for the unstable conditions \#1 and \#2 from Jackson and Lyford (1999). We assume $c_{z}=c_{y}$ under the unstable conditions after Sutton (1953). Jackson and Lyford (1999) provided a detailed discussion on the effects of the atmospheric conditions on the pollen dispersal distance using the parameter sets above. The same sets of parameters are used here to estimate the RSAP in the hypothetical landscape.

Estimation of RSAP: A moving-window linear regression method is introduced here to estimate the distance at which the likelihood function score approaches an asymptote (Fig. 2; see also the theory review above). This method fits a straight line to the data points within the moving-window and tests whether the slope is statistically different from zero or not. The distance at and beyond which the slope becomes consistently not different from zero $(P>0.05)$ is defined as the estimate for the RSAP. This method approximates the slope at a given distance (i.e. the middle of the moving-window) using regression, instead of estimating the slope at a point at the distance using the first derivative of the curve of the likelihood function score. Therefore, the selected width of the moving-window will affect the RSAP estimate. We changed the width of the moving-window from 200 to $400 \mathrm{~m}$ to evaluate how the shape of the curve of the likelihood function score and the width selection would interact. The source code of the programme for this method is written in $\mathrm{C}++$ by Sugita (unpublished).

Evaluation of the pollen dispersal model under the neutral condition as a method of distance-weighting the plant abundance: The pollen data were simulated for the 30 lakes in the hypothetical landscape (Fig. 1; Table 3) under the neutral, unstable \#1 and unstable \#2 conditions (Table 5). These pollen data were then used as the input into the sub-model 3 of the ERV model alongside the plant abundance data distance-weighted by the RS model under
Table 5 Values of the parameters $\left(n, c_{z}\right.$ and $\left.c_{y}\right)$ representing neutral, unstable \#1 and unstable \#2 conditions in the simulations

Fig. 2 Moving-window regression to estimate the relevant source area of pollen sensu Sugita 1994. The relevant source area of pollen is estimated as the area within the distance at which the slope of the regression line between the $\log$ likelihood function score from the ERV models and the distance from the lake shore becomes consistently not significantly different from zero $(P>0.05)$ (see text for more explanations). The width of the moving-window varies from 200 to $400 \mathrm{~m}$ for the analysis (Table 6)

\begin{tabular}{llll}
\hline & $n$ (empirical constant) & $\begin{array}{l}c_{z} \text { (diffusion constant } \\
\text { along vertical axis) }\end{array}$ & $\begin{array}{l}c_{y} \text { (diffusion constant } \\
\text { along horizontal axis) }\end{array}$ \\
\hline Neutral condition & 0.25 & 0.12 & 0.21 \\
Unstable condition \#1 & 0.20 & 0.21 & 0.21 \\
Unstable condition \#2 & 0.20 & 0.35 & 0.35 \\
\hline
\end{tabular}

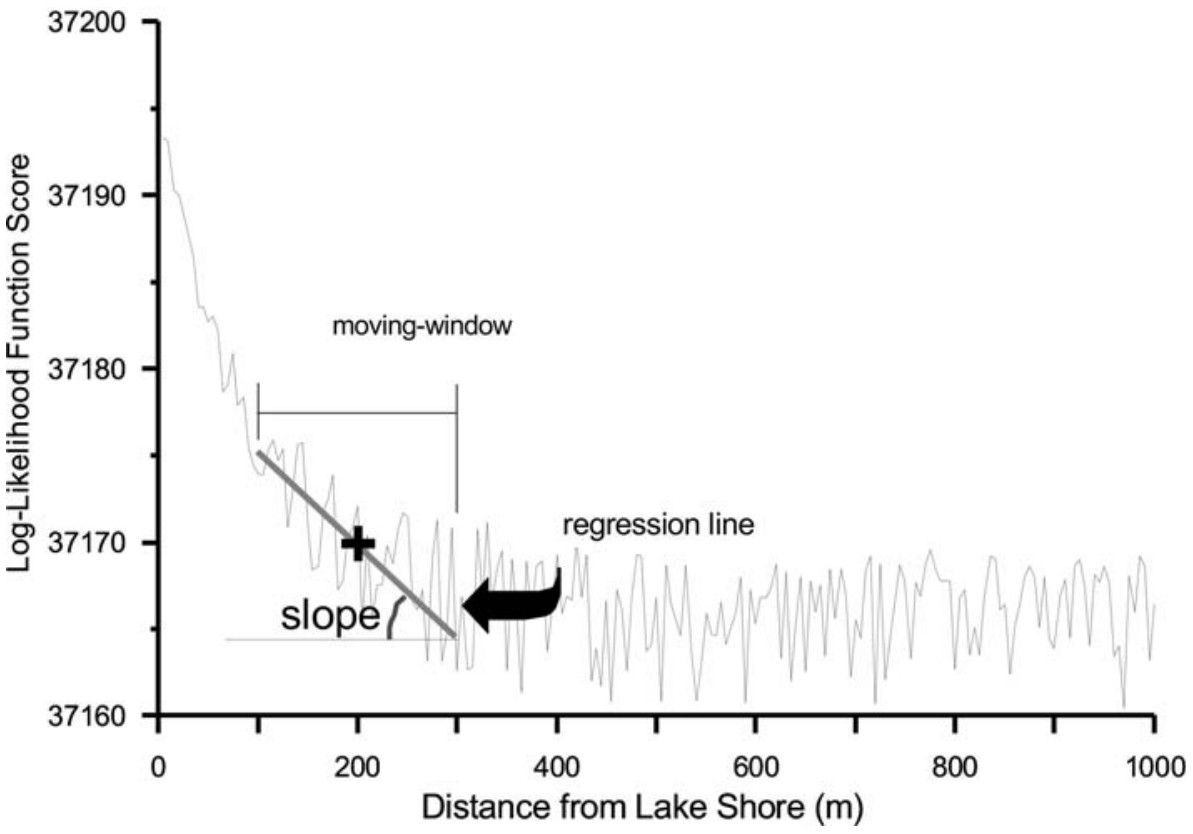


the neutral condition (Sugita et al. 1999). These simulations were made to evaluate the biases caused by the mismatch of the atmospheric conditions assumed in producing the pollen data and the distance-weighted plant abundance data. The RSAP was estimated by the movingwindow regression method described above.

Results: The likelihood function scores show an asymptotic pattern under the neutral, unstable \#1 and unstable \#2 conditions (Fig. 3). Although it fluctuates a little, the likelihood function score shows no major changes beyond $500 \mathrm{~m}$ in all cases. The estimates of the RSAP become bigger as the width of the moving-window increases from 200 to $400 \mathrm{~m}$, which was expected (Fig. 3; Table 6).

When using a moving window of $300 \mathrm{~m}$, RSAP is identified at a distance of 430,435 and $500 \mathrm{~m}$ under the neutral, unstable \#1 and unstable \#2 conditions, respectively (Fig. 3; Table 6). Pollen dispersal patterns and distance could be significantly different for individual taxa

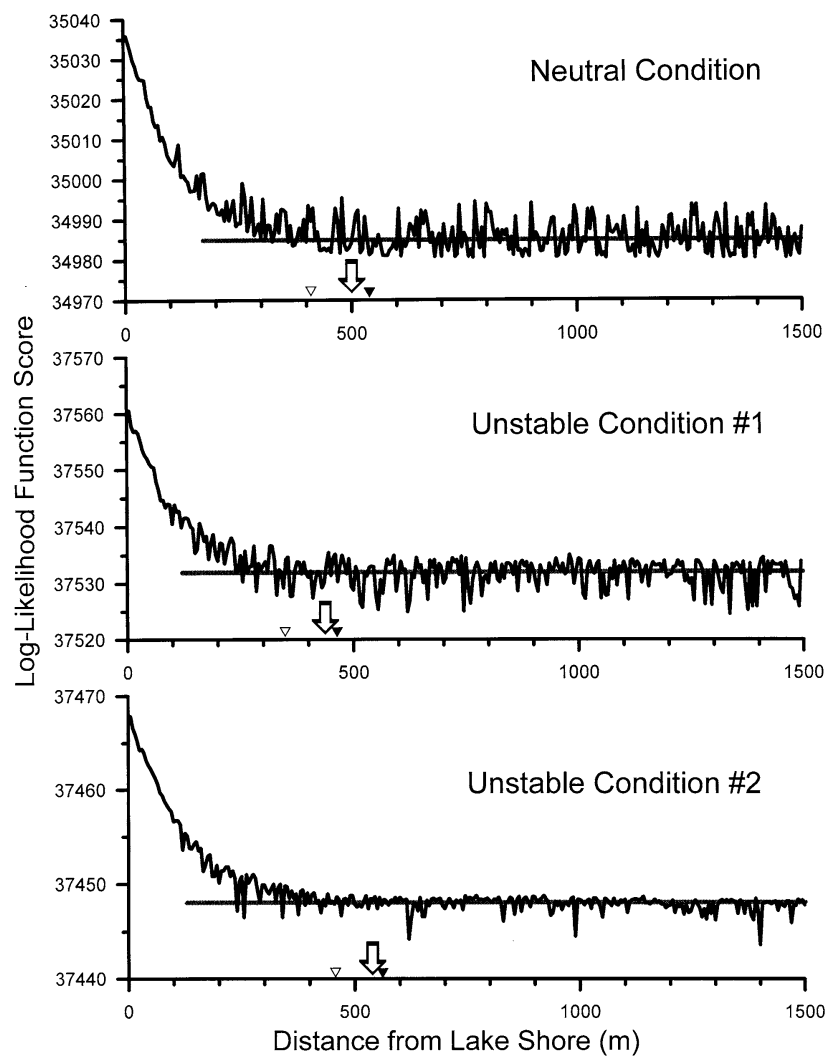

Fig. 3 Changes in the log likelihood function score and the estimates of the relevant source area of pollen under three atmospheric conditions. Parameters for the atmospheric conditions are listed in Table 5. Arrows (downwards arrow), unfilled triangles (open inverted triangle) and solid triangles (filled inverted triangle) show the estimates of the relevant source area of pollen when the width of the moving-window is 200, 300 and $400 \mathrm{~m}$, respectively. The grey horizontal line represents the mean values of the likelihood function scores between 500 and $1,500 \mathrm{~m}$ in each atmospheric condition
Table 6 Estimates of RSAP in three different atmospheric conditions

\begin{tabular}{llllll}
\hline Moving-window (m) & 200 & 250 & 300 & 350 & 400 \\
Neutral (m) & 410 & 480 & 500 & 485 & 540 \\
Unstable \#1 (m) & 345 & 350 & 435 & 460 & 465 \\
Unstable \#2 (m) & 455 & 475 & 540 & 560 & 560
\end{tabular}

The values of the parameters $n, c_{z}$ and $c_{y}$ are listed in Table 5. The estimates of the RSAP are obtained using a moving-window linear regression method. The moving-window varies from 200 to $400 \mathrm{~m}$ (see text for more explanations)

under those different atmospheric conditions. For example, when pine pollen is considered, $50 \%$ of pine pollen comes from within 1,640, 4,720 and 36,000 $\mathrm{m}$ under the neutral, unstable \#1 and unstable \#2 conditions, respectively [as indicated in Jackson and Lyford 1999; based on the Prentice model (Prentice 1985, 1988)]. However, the RSAP in the heterogeneous vegetation varies between 430 and $500 \mathrm{~m}$ under the three conditions, which is relatively a much smaller difference.

When we use the pollen counts simulated under the unstable \#1 condition and the distance weighted plant abundance calculated with the RS model under the neutral condition, the RSAP is estimated at $455 \mathrm{~m}$. This value is comparable to the estimate, $435 \mathrm{~m}$, under the unstable \#1 condition (Table 6; Fig. 3). When the pollen counts under the unstable \#2 condition are used, the RSAP is at $505 \mathrm{~m}$, also comparable to the estimate, $500 \mathrm{~m}$, under the unstable \#2 condition (Table 6; Fig. 3). These results suggest that the RS model under the neutral condition is appropriate to distance-weight the plant abundance. Even when the pollen data are obtained in the unstable conditions, with those plant abundance data, the ERV model provides robust estimates of the RSAP.

The effect of vegetation structure/patterning and composition on the RSAP (Marie-José Gaillard and Jane Bunting)

The aim of this experiment is to further test the results obtained by Sugita et al. (1999) showing comparable RSAPs for tree- or herb-dominated landscapes with comparable mosaic-structures by examining the following question: How does variation in the size of open-land patches and in total open land cover affect RSAP?

Methods: Our basic scenario mimics a landscape dominated by common Holocene deciduous trees on drained soils (Quercus, Ulmus, Corylus: $80 \%$ of the landscape), wet soils (Alnus, Betula: 10\%), and dry, sandy soils (Pinus: $10 \%)$. Openings within the forested landscape are represented by typical pasture and hay meadow herbaceous pollen taxa (Poaceae, Plantago lanceolata and Rumex acetosa/acetosella). The three tree communities form the matrix, and the herbaceous "openings" are represented by 
Table 7 Composition of communities in the landscape designs of example no. 2

\begin{tabular}{lll}
\hline Community & Basic & Reversed \\
\hline $2(80 \%$ of matrix $)$ & Quercus $70 \%$, Ulmus $20 \%$, Corylus $10 \%$ & Poaceae 90\%, Plantago 5\%, Rumex 5\% \\
$3(10 \%$ of matrix $)$ & Pinus $100 \%$ & Calluna $100 \%$ \\
$4(10 \%$ of matrix $)$ & Alnus $50 \%$, Betula $50 \%$ & Cyperaceae $80 \%$, Potentilla $20 \%$ \\
$5(160$ m radius circles $)$ & Poaceae $90 \%$, Plantago $5 \%$, Rumex $5 \%$ & Quercus $70 \%$, Ulmus $20 \%$, Corylus $10 \%$ \\
\hline
\end{tabular}

circular patches. A "reversed scenario" mimics a landscape dominated by open land in which patches of wooded vegetation are scattered. In this case, three herb communities form the matrix, i.e. Poaceae-Plantago lanceolataRumex acetosa/acetosella (80\%), Calluna (10\%) and Cyperaceae-Potentilla (10\%), representing pastures and hay meadows, heaths and wet flushes, respectively. Tree patches are composed of Quercus, Ulmus and Corylus (Table 7; Fig. 4). Three sub-scenarios were used: 10, 50 and $80 \%$ patches. Each scenario was run for the two simulated landscapes "basic" (PB-10, PB-50, PB-80) and "reverse" (PB-10-R, PB-50-R, PB-80-R), making a total of six scenarios. Three replicates of each scenario were created, each $20 \mathrm{~km} \times 20 \mathrm{~km}$ in overall area, using $50 \mathrm{~m}$ cells within the grid (i.e. each grid was $400 \times 400$ pixels

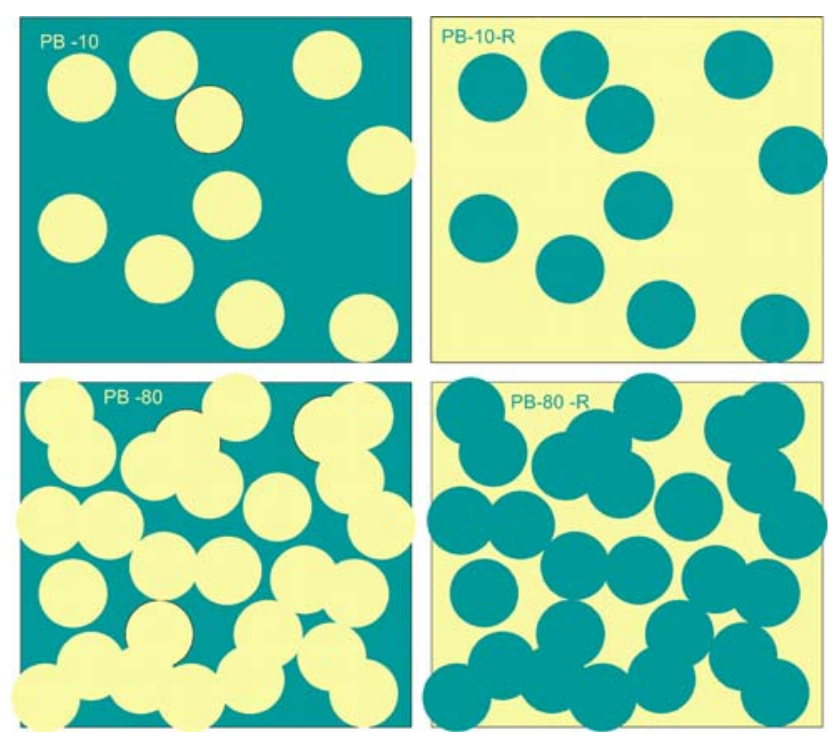

Fig. 4 Landscape scenarios for example no. 2, created in the MOSAIC programme according to the characteristics listed in Table 7 (simplified graphic presentation). To the left, basic scenario, i.e. matrix (green) of three communities of trees (Quercus, Ulmus, Corylus: 80\%; Alnus, Betula: 10\%; Pinus: 10\%) with 160 m radius patches (yellow) of a single herb community (Poaceae, Plantago, Rumex), PB-10 $=10 \%$ herb patches, PB- $80=80 \%$ herb patches. To the right, reverse scenario, i.e. matrix (yellow) of three communities of herbs (Poaceae: $80 \%$; Calluna: 10\%; Cyperaceae, Potentilla: $10 \%$ ) with $160 \mathrm{~m}$ radius patches (green) of a single tree community (Quercus, Ulmus, Corylus), PB-10-R $=10 \%$ tree patches, $\mathrm{PB}-80-$ $\mathrm{R}=80 \%$ tree patches in size). Ten lakes (50 $\mathrm{m}$ in radius) were randomly positioned in the central $4 \mathrm{~km} \times 4 \mathrm{~km}$ block of each replicate, giving a total of 30 sample points for each scenario. Vegetation composition was derived in sequential $50 \mathrm{~m}$ wide rings from the lakes out to $2,000 \mathrm{~m}$. Quercus was used as the reference taxon for ERV-model analysis wherever possible.

Results: RSAP (Fig. 5) is distinctly greater ( $>1,000 \mathrm{~m}$ ) in the two scenarios with high NAP percentages, PB-10-R (90\% NAP, three communities) and PB-80 (80\% NAP, single community), than in the other four (ca. $750 \mathrm{~m}$ ). The landscape structure and model parameters were identical; therefore these changes are likely to be due to either (a) biological factors - fall speed of pollen and/or PPEs, or (b) scattered distribution of some rarer taxa within the landscape. In our simulated landscapes, variation in the weighted mean PPEs between simulations (see mean RPP values in Fig. 5) is the most apparent trend. Lower mean weighted PPE leads to increased RSAP, if the landscape is clearly dominated (more than $50 \%$ ) by species characterized by low PPEs.

\section{Estimating RSAP for different lake sizes in the patchy} cultural landscape of southeast Estonia (Anneli Poska and Siim Veski)

The vegetation cover of the present day patchy cultural landscape of southeast Estonia consists of an intricate mixture of different forest types, crop fields and grasslands with a slight prevalence of woods (Fig. 6). Since the investigation area is situated at the southern limit of the boreo-nemoral forest zone, two deciduous tree taxa (Alnus spp. and Betula spp.) and two coniferous species (Picea abies and Pinus sylvestris) represent the major part of the woodlands. The main crops are cereals, while the grasslands are dominated by Poaceae.

Methods: In order to know the lake size which best displays local-scale landscape changes in their pollen assemblages, and to estimate the area of the landscape reflected by the pollen record, the RSAP was calculated for 36 lakes placed randomly in a $50 \mathrm{~km} \times 50 \mathrm{~km}$ plot of the CORINE (COoRdination of INformation on the Environment) vegetation map of southeast Estonia. The vegetation classes used in the CORINE map were 

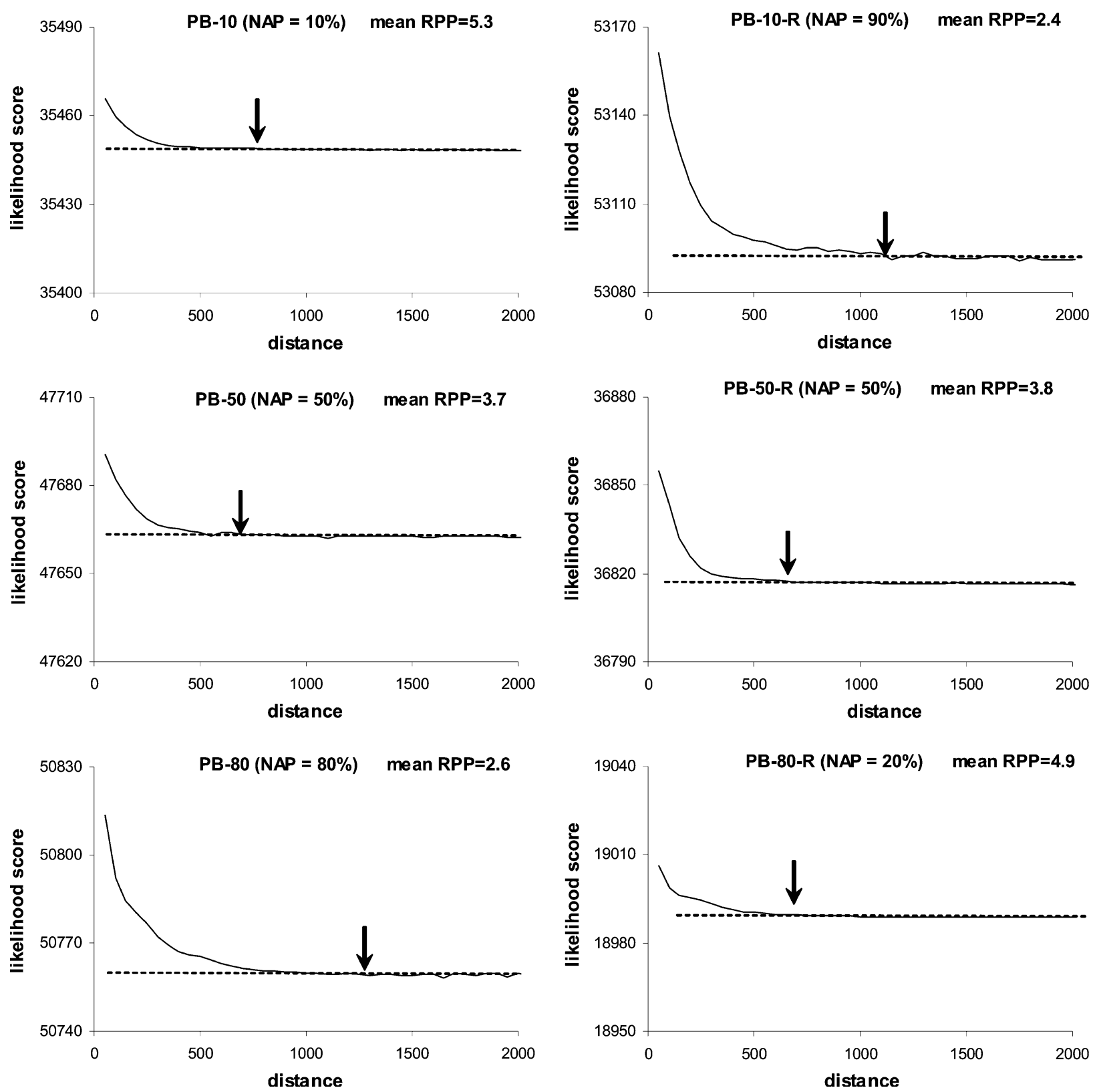

Fig. 5 Likelihood function scores obtained in the six simulations using simplified hypothetical landscapes in example no. 2

simplified and grouped into seven classes (Fig. 6). Six data sets, with lakes of 50,100, 250, 500, 1,000 and $2,000 \mathrm{~m}$ radius were generated. Vegetation composition was derived in sequential $100 \mathrm{~m}$ wide rings from the lakes out to $7,000 \mathrm{~m}$.

Results: The simulation results show that the RSAP of lakes with $50-250 \mathrm{~m}$ radius is $\leq 2,000 \mathrm{~m}$. Lakes with radii larger than $500 \mathrm{~m}$ were found to represent regional vegetation, e.g. the RSAP is larger than the area of mapped vegetation (Fig. 7). These results agree with the definition of large lakes in terms of pollen representation of regional vegetation (Sugita 2007a).
Testing the interpretation of pollen assemblages in terms of vegetation changes and quantitative vegetation characteristics

Detection of small Picea populations by pollen analysis (Thomas Giesecke and Henrik von Stedingk)

Norway spruce ( $P$. abies), one of the most important Scandinavian forest trees, spread into Sweden after the last glaciation. The timing of this spread has been under debate, since evidence from macrofossil data indicating an early arrival (Kullman 1996) contradicts earlier pollen data 
Fig. 6 Landscape for example no. 3: Simplified CORINE map $(1: 100,000)$ of southeast Estonia $\left(27^{\circ} 00^{\prime} \mathrm{E}, 57^{\circ} 50^{\prime} \mathrm{N}\right)$. The number of vegetation classes of the CORINE map was reduced by grouping them into eight larger classes. The proportion of a class in the investigated landscape is given in brackets

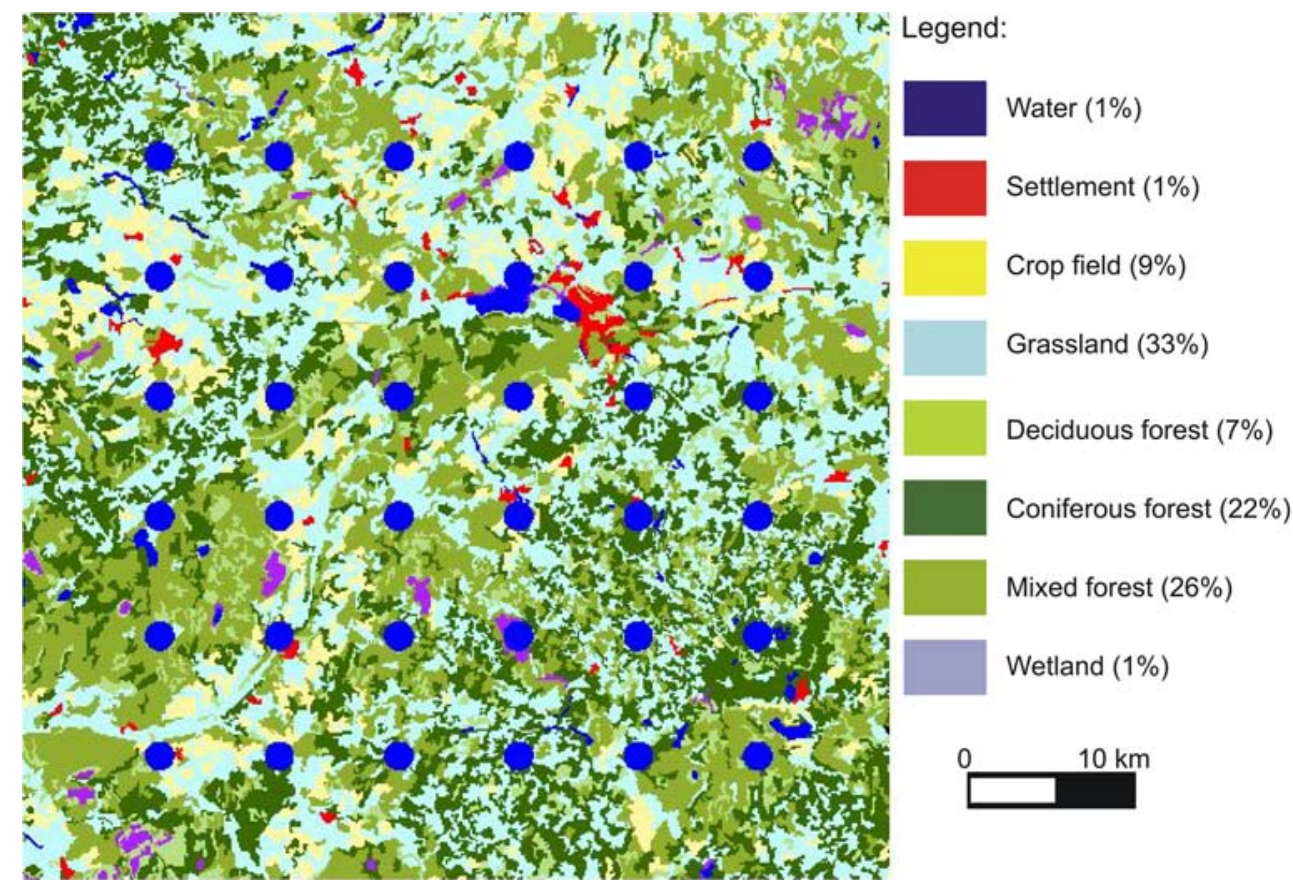

Fig. 7 RSAP for different basin sizes in the landscape of southeast Estonia (Fig. 6). The RSAP for lakes with $50-250 \mathrm{~m}$ radii is estimated to an area of $1,500-2,000 \mathrm{~m}$ radius

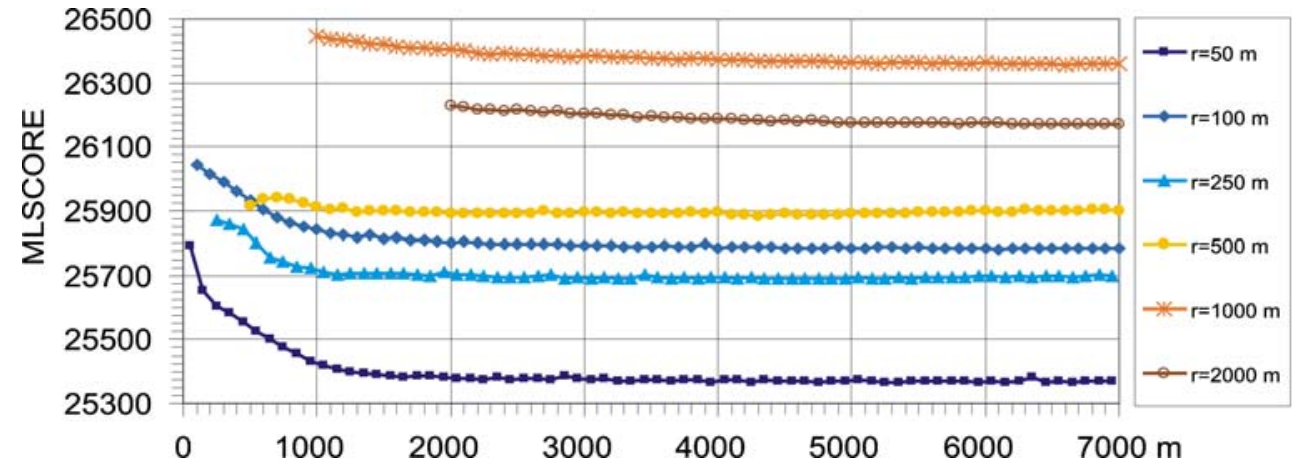

$100 \mathrm{~m}$ radius. The pixel width was set to $1 \mathrm{~m}$ in scenarios 1 and 2 (i.e. landscape area of $750 \mathrm{~m} \times 750 \mathrm{~m}$ ), and to $4 \mathrm{~m}$ in scenario 3 (i.e. landscape area of $3 \mathrm{~km} \times 3 \mathrm{~km}$ ). The same nine fixed sampling points were used in all grids and the distance to the edge of the nearest Picea patch was recorded in metres (Fig. 8; Table 8). Simulations were run 20 times for each scenario using the Prentice's model. Pollen loadings were simulated at each $\mathrm{m}$ from the sampling points out to the border of the landscape.

Results: The lowest percentages of Picea predicted in each simulation experiment are indicated in Table 8, as well as the percentage of sampling points with a prediction of $>5,>1-5,>0.2-1$ and $>0.1-0.2 \%$ of Picea. Figure 9 shows how fast pollen percentages of Picea drop with distance from the Picea stand. Sampling points well inside the Picea stands reached percentages between 20 and 30\% for all stand sizes, while sampling points at the edge of the $5 \mathrm{~m}$ radius stands scored values as low as $1.4 \%$. In all three 


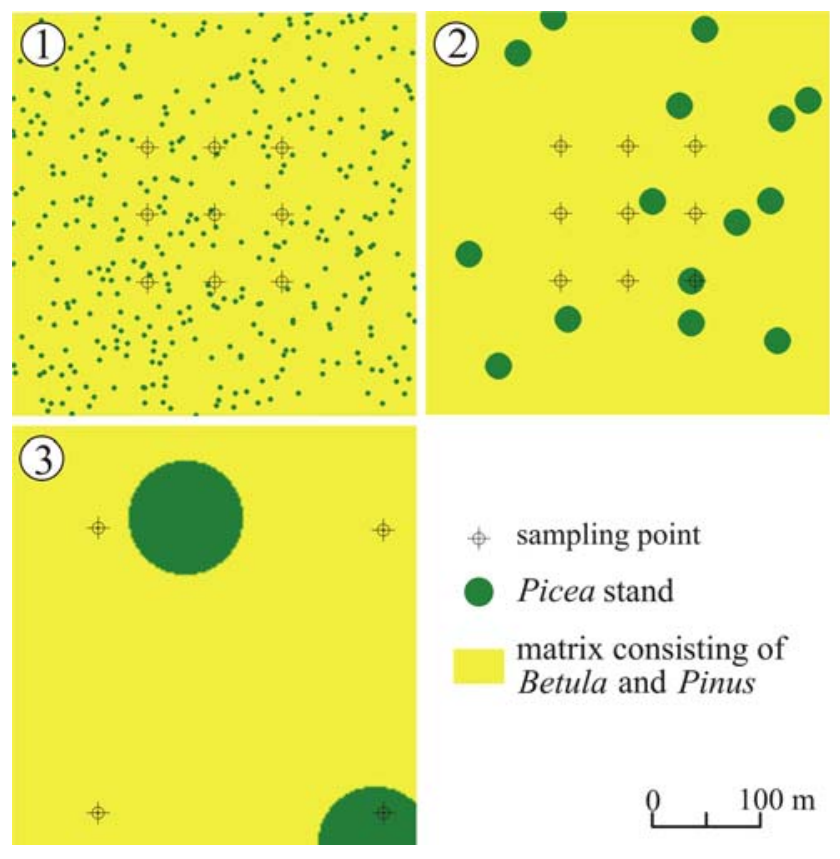

Fig. 8 Examples of random landscapes used in the three scenarios of example no. 4. Note that only a small proportion of the landscape is shown. Erratum: in scenario 3, the sampling points should be identical as in scenarios 1 and 2. Radius of Picea patches: $1.5 \mathrm{~m}$, 2. $25 \mathrm{~m}$, and $3.100 \mathrm{~m}$ scenarios the pollen percentages dropped below $1 \%$ only a few metres away from the Picea stand. The drop in Picea pollen percentages is steepest for small Picea stands and more gradual for the larger stands. Further simulations exploring the representation of Picea stands in pollen records are presented in Giesecke (2005).

Model simulations, landscape reconstruction and archaeological questions (Kari Hjelle, Catherine Langdon and Christopher Caseldine)

Archaeologists wishing to understand the environmental context of sites have consistently looked to palaeoecologists to provide answers to a number of key questions: what was the composition and structure of the original landscape faced by early communities? What was the impact of settlement and agriculture, e.g. what was the size of the openings utilized for grazing and agriculture, and how were cultural landscapes actually structured in terms of the relationship between disturbed and undisturbed vegetation communities? The simulation approach offers an exciting opportunity to tackle these questions and provide landscape scenarios to test against empirically derived palynological sequences, particularly for specific time slices defined both
Table 8 Information on the landscape scenarios used in the simulations of example no. 4
Fig. 9 Percentage of Picea pollen at the sampling point plotted against distance from the sampling point to the edge of a Picea stand (note: logarithmic scale); yellow: $r=5 \mathrm{~m}$ (scenario 1), red: $r=25 \mathrm{~m}$ (scenario 2), blue: $r=100 \mathrm{~m}$ (scenario 3 )

\begin{tabular}{llll}
\hline Scenario & $r=5 \mathrm{~m}$ & $r=25 \mathrm{~m}$ & $r=100 \mathrm{~m}$ \\
\hline Greatest distance to the edge of a Picea stand $(\mathrm{m})$ & 46 & 192 & 689 \\
Lowest percentage of Picea in simulations & 0.11 & 0.06 & 0.03 \\
$\%$ of sampling points with $>5 \%$ Picea pollen & 4 & 6 & 2 \\
\% of sampling points with $>1-5 \%$ Picea pollen & 5 & 7 & 2 \\
$\%$ of sampling points with $>0.2-1 \%$ Picea pollen & 44 & 23 & 11 \\
$\%$ of sampling points with $>0.1-0.2 \%$ Picea pollen & 100 & 73 & 32 \\
\hline
\end{tabular}

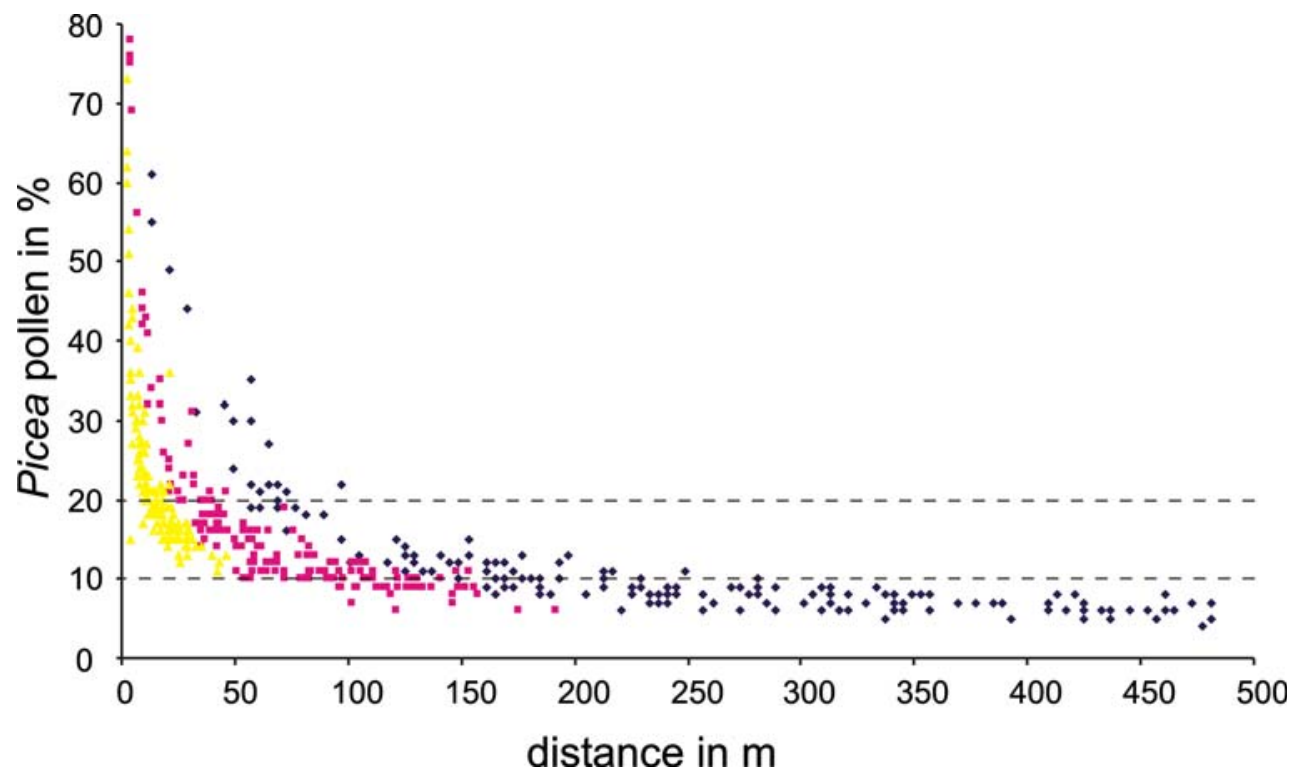


Fig. 10 Location of the site Caislean on Achill Island (western Ireland; example no. 5)

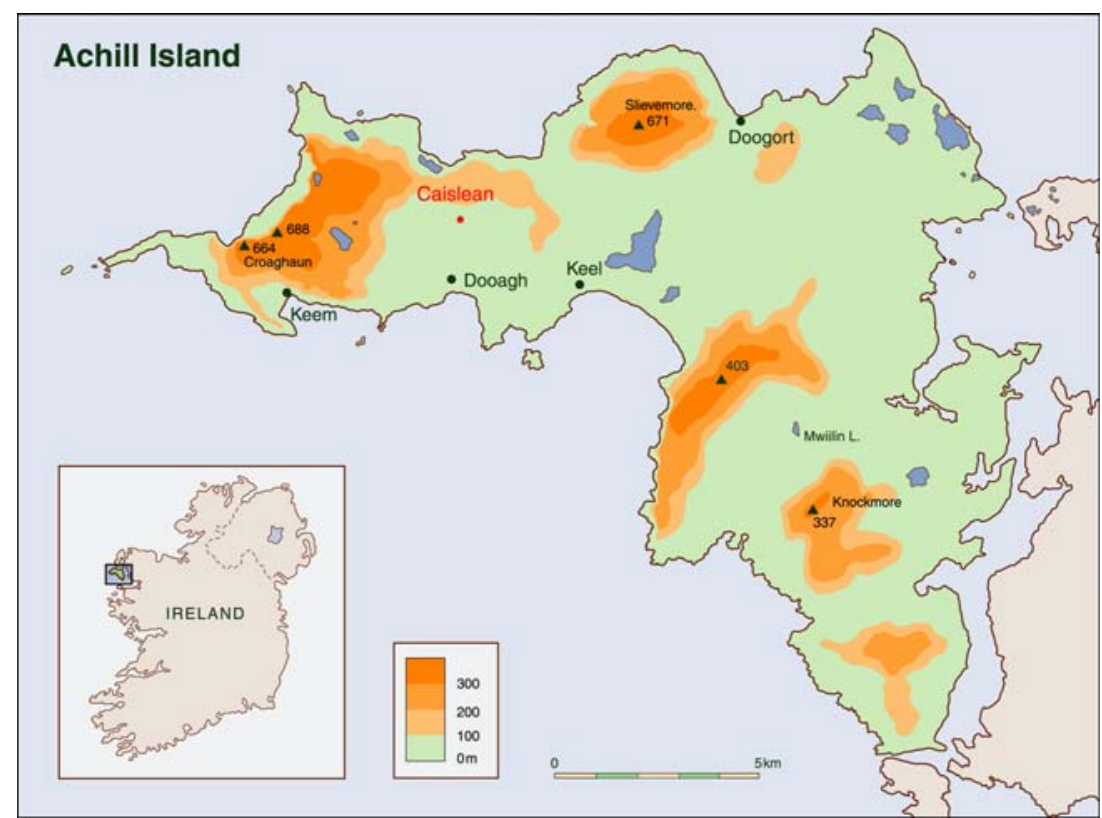

by archaeological and palaeoecological evidence. Two examples show the possibilities of such an approach:

Achill Island: At Achill Island, Western Ireland, archaeological survey has revealed evidence for human settlement throughout prehistory. Pollen analysis of a small basin site $(30 \mathrm{~m} \times 30 \mathrm{~m})$ at Caislean (Fig. 10) provides pollen assemblages covering the same period from which landscape modification may be determined. Hypothetical landscape structures of the surrounding area have been modelled for a series of time slices. Here, a time slice for the Early Neolithic (ca. $5000{ }^{14} \mathrm{C}$ years B.P.) prior to the first palynological indications of human activity is described, concentrating on possible woodland structures. The site and the period have a number of advantages for testing the approach: the pollen flora is relatively poor with only a few major tree and herb taxa (Pinus, Quercus, Ulmus, Corylus, Poaceae and Calluna); at least $40 \%$ of the area reconstructed, $1 \mathrm{~km}^{2}$, was known to be covered by peat (Calluna-Poaceae) at the time; pollen input by prevailing winds from the west may be assumed to be minimal due to the proximity to the Atlantic. Three different scenarios were designed for which vegetation structures were as follows (Fig. 11): (a) large uniform blocks of woodland and peat arranged around the site; (b) a twofold division between peat and a homogeneous mix of the other taxa; and (c) a basically twofold division but the non-peat block comprises small circles within a matrix. Pollen assemblages at a central point in the simulated landscape were calculated in a single model run for each scenario. The predicted frequencies for the main taxa are compared to those derived empirically from the pollen core (Fig. 12). Overall the circle structure (c) shows the closest fit,

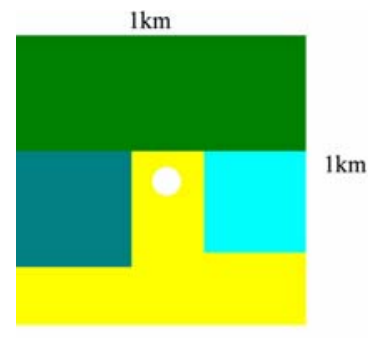

(a) Blocks of communities

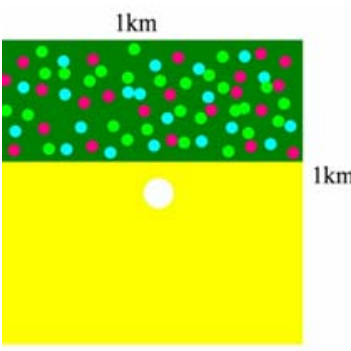
(c)
non-peat block

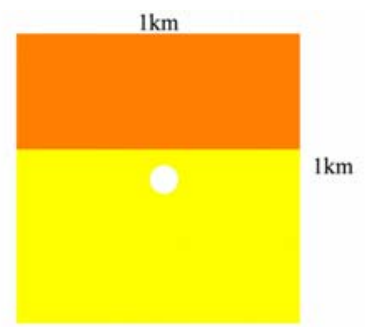

(b) Homogenous mix of species
in non-peat block

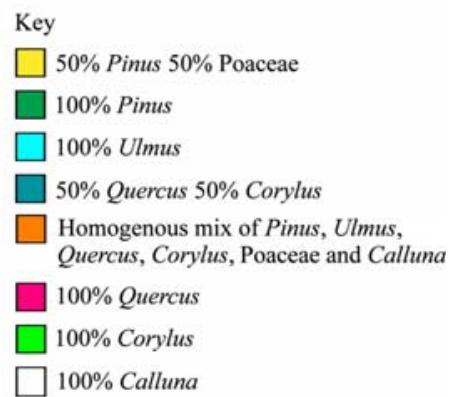

Fig. 11 Three landscape scenarios (a-c) for example no. 5. See text for more explanations

although the block structure (a) produces also a very close fit. The homogeneous run is most dissimilar, although none are radically different from the fossil situation.

Sugita (1994), Broström et al. (1998) and Sugita et al. (1999) have emphasized the importance of background pollen in determining pollen assemblages. Despite the low inferred background input in our case, these simulations were run with a variety of levels of island-based pollen to estimate the sort of envelope of conditions that could have 
Actual vs simulated pollen percentages for Achill Island with no background pollen component

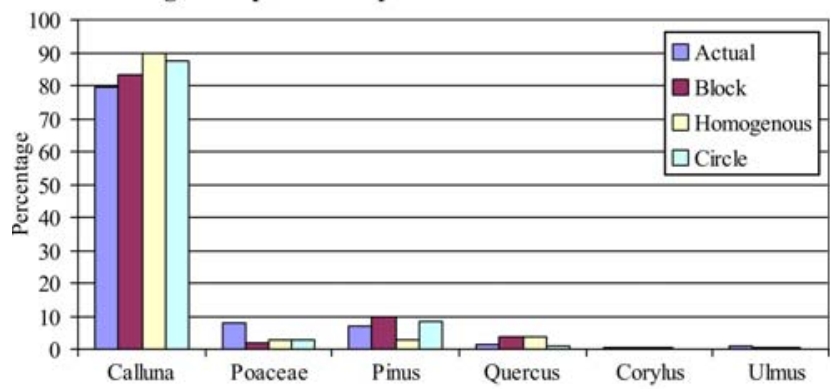

Actual vs simulated pollen percentages for Achill Island with a homogenous background pollen component

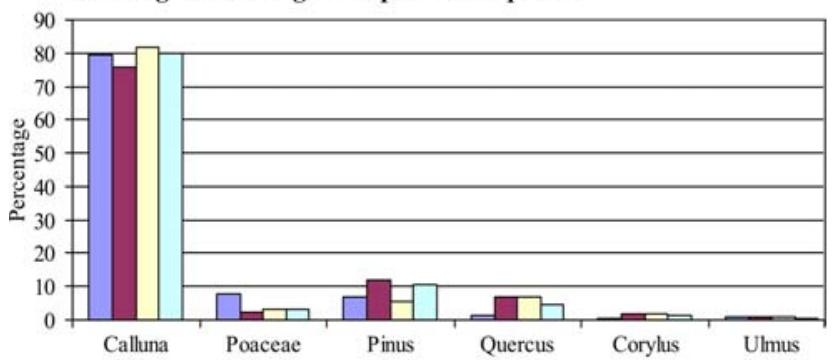

Actual vs simulated pollen percentages for Achill Island with a pine background pollen component

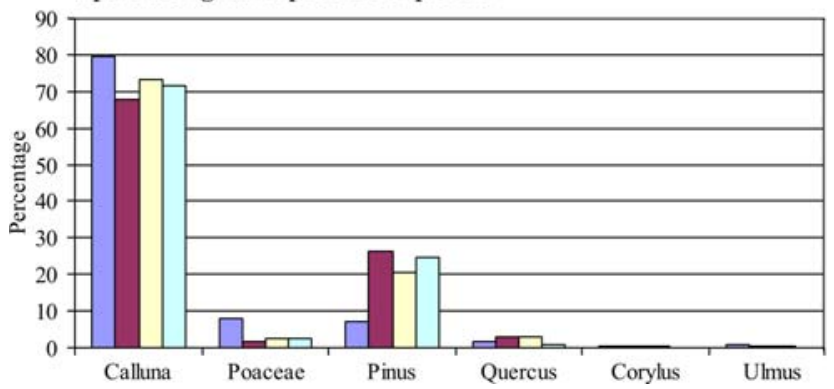

Fig. 12 Model-predicted pollen loadings of six taxa for the three scenarios in example 5 (Achill Island; Fig. 11) compared with the empirical pollen data ("actual") from the Caislean site (Fig. 10). The results are presented for three different sets of simulations in terms of the background pollen component chosen in the model run

occurred (Fig. 12). The two backgrounds are extreme ends of the likely envelope from predominantly Pinus to a relatively even homogeneous mix. The results show that, in general, this background pollen does influence the relative impact of local taxa (in this case predominantly Calluna) and makes distinct differences from the fossil data. The scenario (c) (circle structure) with a background pollen produced by a homogenous mix of the species shows the best fit to the empirical pollen assemblage. The next step in the analysis is to revise the structures shown in Fig. 10 to see how much these need to be modified to take into account the background impacts demonstrated, thus narrowing the sort of landscape structures likely to have existed. Further experiments of this kind and reconstructions of vegetation in archaeological contexts were published recently in

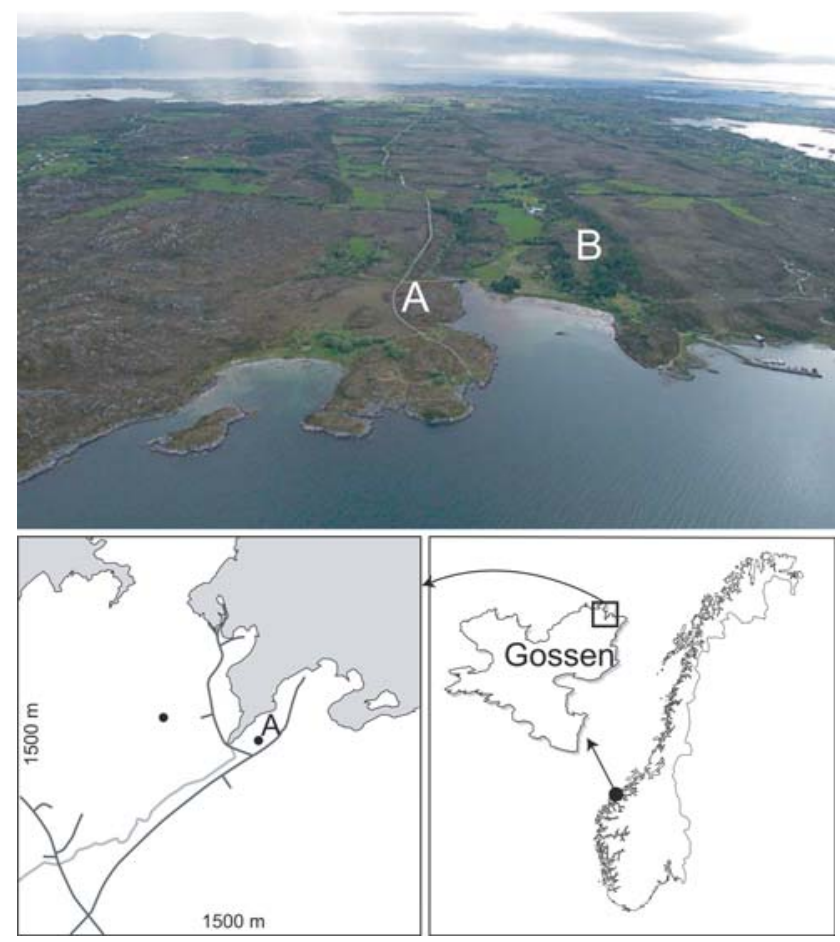

Fig. 13 Location of the two sites for the pollen records used in example no. 5 (Gossen Island, western Norway)

Caseldine and Fyfe (2006) and Caseldine et al. (2007a) (see also Caseldine et al. 2007b, this volume).

The Island Gossen: At the island Gossen in Western Norway (Fig. 13), archaeological surveys revealed a large number of settlements from the Stone Age, as well as traces of settlements from the Bronze and Iron Ages. In the north-eastern part of the island pollen diagrams from two sites ca. $400 \mathrm{~m}$ from each other show different vegetation developments from the Early Iron Age onwards. Settlement areas from the Iron Age with postholes from houses and plough marks are found on dry, sandy ground close to the sea (including site A), whereas bogs developed in the inland region (including site B). Today, site A is covered by heather, but at a level dated to about A.D. 800 , the pollen assemblage is dominated by Poaceae, Alnus, Betula and Pinus, whereas Calluna has low pollen percentages. This is interpreted as meadow/pasture on dry ground surrounded by forest of Betula, Pinus and Alnus. At site B, the pollen assemblages dated to A.D. 800 indicate heathland with a mosaic of Calluna and Cyperaceae.

The landscape scenario $(1,500 \mathrm{~m} \times 1,500 \mathrm{~m})$ used in the present model experiment is strongly simplified in terms of vegetation structure and composition. However, it takes into account topography and humidity characteristics of the site, and uses archaeological information from the reconstructed time period (Fig. 14). Only five species were used in the simulations: Alnus, Betula, Pinus, Calluna and Poaceae/Cyperaceae. These taxa represent 90 and $83 \%$ of 


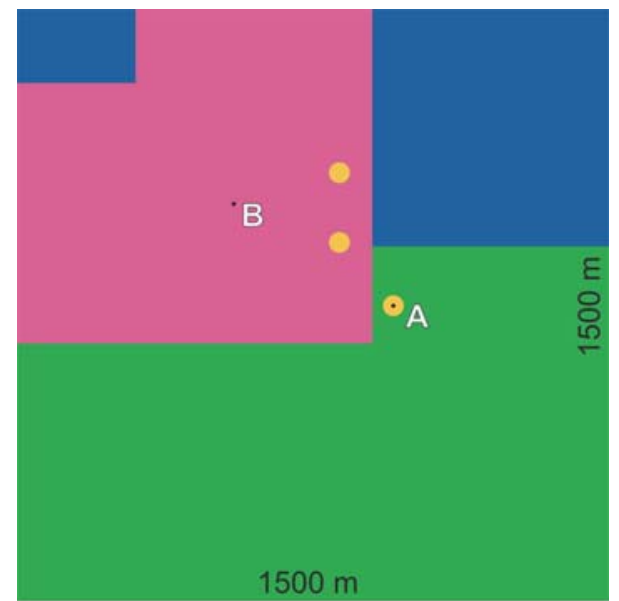

$40 \%$ Betula, 30\% Pinus, 30\% Alnus $80 \%$ Poaceae, $20 \%$ Alnus

$80 \%$ Calluna, 20\% Cyperaceae/Poaceae Water

Fig. 14 Landscape scenario used in example no. 5 (Gossen Island; Fig. 13). See text for more explanations

the empirical pollen assemblages from ca. A.D. 800 at sites $\mathrm{A}$ and $\mathrm{B}$, respectively. The simulations were carried out using a wind speed of $5 \mathrm{~m} / \mathrm{s}$ (mean value for the area today), and a similar regional plant abundance for the two sites. PPEs are from western Norway (Hjelle 1998) for Calluna (1.07) and from Sugita et al. (1999) for the AP taxa. In order to investigate the influence of different PPEs on the simulated pollen percentages, the Swedish PPE for Calluna (4.7) (Broström et al. 2004) was also used as an alternative. Pollen assemblages at sites A and B in the simulated landscape were calculated in a single model run.

Comparisons of the empirical and simulated/predicted pollen percentages (Fig. 15) show great similarities. Although simplified, the hypothetical landscape provides a more precise picture of the possible vegetation at the end of the Iron Age. An opening of the forest of $20 \mathrm{~m}$ radius produces a pollen composition quite comparable to the empirical assemblages from ca. A.D. 800 at site A. Some patches of Alnus probably existed close to the site as well as on wet soils and along rivers, whereas Betula and Pinus dominated drier soils. Calluna heathland may have developed in a large area surrounding site B. The predicted pollen assemblages obtained were significantly different depending on the PPE used for Calluna (Fig. 15). It shows the importance of testing the reliability of PPEs for different regions (see also Hellman et al. 2008a, b; Broström et al. 2008, this volume).

\section{A first step towards evaluating simulation and model} performance with empirical data (Sheila Hicks and Jarno Mikkola)

Pollen deposition has been monitored for 20 years within the regional forest zones of northern Finland. Vegetation analyses using air photographs are available for an area of
Fig. 15 Model-predicted pollen percentages compared with the empirical pollen data ("actual") for sites $\mathrm{A}$ and $\mathrm{B}$ in the simulated landscape of Fig. 14 using different PPEs for Calluna, i.e. from Norway (simulated N) or from S Sweden (simulated $\mathrm{S}$ )
Site A

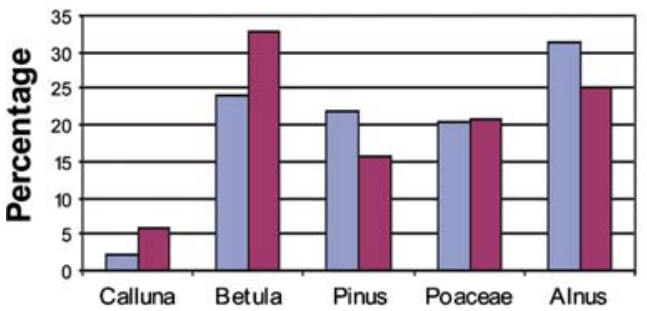

Site B: Simulations using different PPE

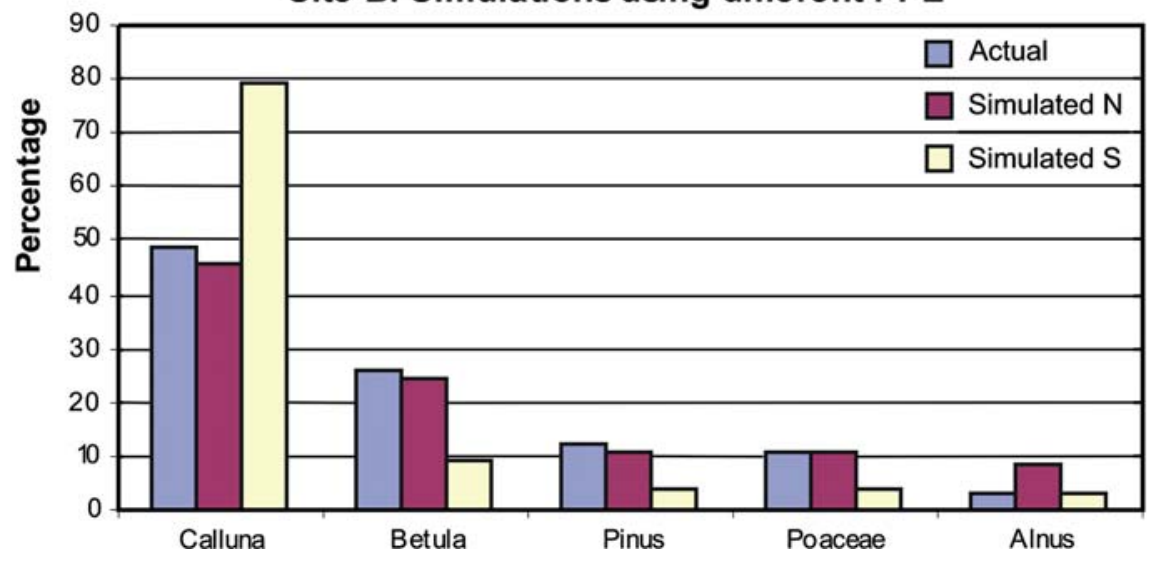


Fig. 16 Example no. 6: vegetation map at Kevo (northern Finland) for a $2 \mathrm{~km} \times 2 \mathrm{~km}$ area centered on the pollen trap (marked by the star). On the right: \% cover of each vegetation class within a circle of $1,000 \mathrm{~m}$ radius around the pollen trap

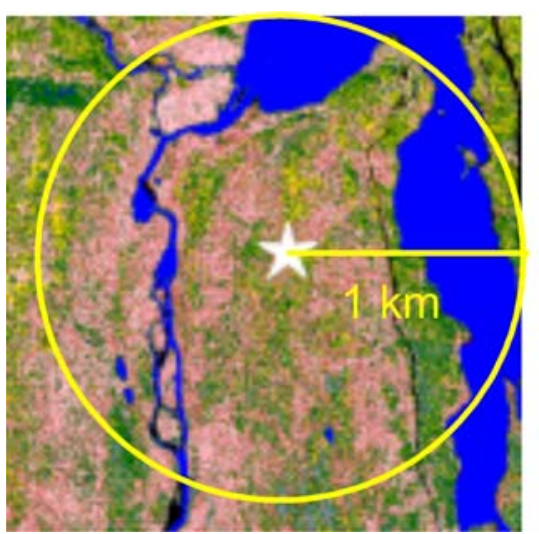

\begin{tabular}{lr}
\hline Pine forest & 21.0 \\
Mountain birch forest & 22.0 \\
Grassland & 0.5 \\
Empetrum heath & 7.5 \\
Dwarf shrub heath & 23.0 \\
Wet herb and grass mire & 3.0 \\
Water & 21.0 \\
Unvegetated area & 2.0
\end{tabular}

several kilometres around some of these monitoring stations. These data (pollen deposition and vegetation data) can potentially be used to evaluate the POLLSCAPE model. The Kevo site, in northern Finnish Lapland, is selected. The regional vegetation is dominated by mountain birch (Betula pubescens ssp. tortuosa) but there are both local stands of pine in the valleys and isolated pines on the higher areas (Fig. 16). The site for pollen monitoring is the centre of a small mire (ca. 50 m radius, 0.75 ha) the surface of which supports sedges and dwarf shrubs.

Methods: The landscape scenario $(2 \mathrm{~km} \times 2 \mathrm{~km}$, Fig. 17) reproduces as closely as possible the remotesensed vegetation analysis in terms of the percentage cover of the different vegetation classes (but with some classes combined, Table 9). The simulation was run for a mire of the same size as the pollen monitoring mire using a wind speed of $3.6 \mathrm{~m} \mathrm{~s}^{-1}$ (the average speed at Kevo in June). Pollen loading for a point in the centre of this mire was calculated from the simulated data and compared with the actual pollen loading recorded in the pollen trap (averages

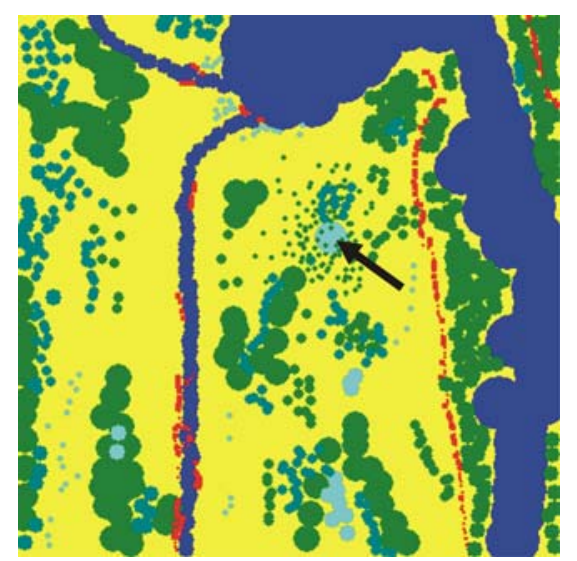

Fig. 17 Landscape scenario created using MOSAIC for example no. 6 (northern Finland) mimicking the vegetation map of Fig. 16. The square is $2 \mathrm{~km} \times 2 \mathrm{~km}$ and the pixel size is $5 \mathrm{~m}$. The arrow indicates the location of the pollen trap of both the whole 20-year monitoring period and of just the last seven years, expressed as $\%$ of the sum of the seven relevant pollen taxa: Pinus, Betula, Betula nana, Empetrum, Total Ericaceae, Poaceae and Cyperaceae, Table 10).

Results: The largest discrepancies between the simulated and empirical pollen loadings are found for Pinus, Betula, Total Ericaceae and Poaceae, where Pinus and Total Ericaceae are underrepresented by the model simulation, while Betula and Poaceae are overrepresented. Possible causes behind these discrepancies may be (a) the use of PPEs from southern Sweden that may not be applicable in northern Sweden, (b) a too simplified simulation where background pollen is not taken into account (too low values of Pinus), or (c) the model itself.

\section{Discussion, conclusions and prospects}

The examples presented above serve to show some ways in which the model and simulations can be used to test the effect of various factors on pollen dispersal and deposition, to explore different scenarios of landscape/vegetation reconstructions and to refute hypotheses, and how empirical data can contribute towards evaluating model performance. The POLLANDCAL network has used the

Table 9 Vegetation cover for the landscape scenario in Fig. 17

\begin{tabular}{lc}
\hline Vegetation class & $\begin{array}{l}\text { \% Cover within } \\
\text { the } 2 \mathrm{~km} \times 2 \mathrm{~km}\end{array}$ \\
\hline Pine forest & 21.1 \\
Mountain birch woodland + dwarf shrub heath & 49.7 \\
Grassland + wet herb and grass mire & 1.3 \\
Empetrum heath & 5.6 \\
Water & 21.1 \\
Unvegetated & 1.2 \\
\hline
\end{tabular}


Table 10 Recorded pollen loading (mean of 20 and 7 years) in Kevo compared with model-predicted pollen loading calculated for a simulated landscape mimicking the "real world" landscape

\begin{tabular}{llllllll}
\hline & Pinus & Betula & Betula nana & Empetrum & Total Ericaceae & Poaceae & Cyperaceae \\
\hline Average \% 20 years & 23.2 & 36.2 & 4.8 & 1.4 & 5.0 & 0.9 & 28.5 \\
Average \% last 7 years & 26.2 & 32.8 & 4.8 & 1.4 & 9.6 & 0.6 & 24.5 \\
Model-predicted pollen loading & 13.8 & 55.6 & 2.6 & 2.0 & 1.1 & 4.9 & 19.7 \\
\hline
\end{tabular}

simulation approach proposed by Sugita (1994) and Sugita et al. (1999) to focus on two main aspects, the prediction of pollen loadings and RSAP. Pollen loadings, either at one point in the centre of a mire or over the entire surface of a lake, have been calculated from both simulated and realworld vegetation situations. RSAP has been estimated under different atmospheric conditions, for landscapes with different structures and patch size, and for different sizes of lake.

\section{Methodological issues}

In the six examples of application, the size chosen for the simulated landscape varies a lot, from $1 \mathrm{~km} \times 1 \mathrm{~km}$ in example 5 to $60 \mathrm{~km} \times 60 \mathrm{~km}$ in example 1 , as well as the number of samples (lakes or bog sites), from 1 in examples 5 and 6 to $\geq 30$ in examples $1-4$. The examples presented here, nos. 4-6 in particular, are very simple, first experiments that need to be expanded to obtain more useful results, which was done in the case of examples 4 (Giesecke 2005) and 5 (Caseldine and Fyfe 2006; Caseldine et al. 2007a, b). Modelling results are more reliable when large simulated or real landscapes (ideally $\geq 50 \mathrm{~km} \times 50 \mathrm{~km}$ ) and a large number of sample sites (ideally $\geq 30$ ) randomly distributed in the landscape are used for calculation of pollen loadings and RSAP (see examples 1-3). In that way the variability in pollen loadings within a landscape can be assessed, and RSAP estimates are more reliable. In examples 4-6 the aim was to predict pollen loading or pollen percentages in simulated landscapes mimicking the real world as closely as possible. In example 4 , landscape plots of $750 \mathrm{~m} \times 750 \mathrm{~m}$ and $3 \mathrm{~km} \times 3 \mathrm{~km}$ were used, each plot being created 20 times, each time with a random distribution of patches, thus resulting in slightly different plots in terms of spatial distribution of patches and taxa, and in a very large number of sites ( 180 per scenario), which is a fully sufficient number. However, the use of larger landscape plots would have been preferable (Giesecke 2005). In example 5 larger landscape plots corresponding to the size of the island around the sites (ca. $5 \mathrm{~km} \times 5 \mathrm{~km}$ at Achill island, and ca. $3 \mathrm{~km} \times 3 \mathrm{~km}$ at Gossen) would have been more appropriate to use. Moreover, using a number of sites distributed randomly in the different landscape scenarios would have provided a range of pollen assemblages for each scenario instead of a single one, which would have offered a better basis for assessment of the results. However, alternative landscape scenarios should be tested to assess whether differences in vegetation/landscape structure would produce significant differences in pollen assemblages. Similarly, in example 6 , a very large landscape of $50 \mathrm{~km} \times 50 \mathrm{~km}$, and a large number of samples distributed randomly within the central part of that landscape, would have been more appropriate for this simulation experiment, as well as the inclusion of background pollen from an area of $400 \mathrm{~km}$ around the site (see example 1).

RSAP: what factors do play a role?

In example 3, the results clearly indicate that basin size plays a major role on the size of the RSAP, as shown earlier by Sugita (1994). In a mosaic landscape comparable to that of southeastern Estonia, lakes with radii larger than $500 \mathrm{~m}$ will provide pollen assemblages representing the regional vegetation of an area larger than $25 \mathrm{~km} \times 25 \mathrm{~km}$, while lakes with radii between 50 and $250 \mathrm{~m}$ will provide pollen assemblages representing the local vegetation within a RSAP of radius $\leq 2,000 \mathrm{~m}$. Using simulations, Nielsen (2003) showed that differences in wind speed would not significantly affect the estimate of the RSAP. The simulation results presented here as example 1 indicate that the RSAP estimates are robust; they are little impacted by the differences in the atmospheric conditions. The leptokurtic nature of pollen dispersal, i.e. a sharp decline near the source and a long tail, contributes to the results. Background pollen coming from beyond the RSAP could be more than 50-60\% of the total pollen loading (Sugita 1994; Calcote 1995). However, as long as the background pollen loading is consistent among sites, the differences in pollen record reflect the differences in plant abundance within the RSAP (Sugita 1994, 1998).

Another important implication of the simulations in example 1 is that the RS model (Sugita et al. 1999) is appropriate for distance-weighting plant abundance when a neutral condition is applied. Even if pollen grains were dispersed and deposited under the unstable conditions, the estimates of the RSAP using a stable condition are robust. This is a very useful information as it would be difficult to estimate the atmospheric conditions prevailing when the 
pollen grains were deposited in the modern or past landscape. A clear understanding of the basic assumptions and limitations of the ERV-models and of the pollen dispersal models help to improve our ability to estimate the spatial scale of vegetation represented by pollen and assess the validity of these models. More modelling studies using a wide variety of landscapes would be necessary to stringently confirm the results of these simulations.

In example 2, the results suggest that the PPEs of the species involved might influence the size of the RSAP when taxa with low or high PPEs are dominating the landscape, i.e. the RSAP become larger when taxa with low PPEs (such as most herbs) represent more than $50 \%$ of the landscape. In the case of NW European landscapes, this would imply that the spatial scale of reconstruction in an open landscape is larger than in a forested or mosaic landscape. These results are confirmed by more recent simulations (Hellman et al. 2008c, d, in press). In landscapes characterized by patches of Poaceae in a matrix of Quercus, Pinus and Alnus, increasing patch size generally resulted in larger RSAP when Poaceae (PPE 1.0) exceeded $50 \%$, while RSAP did not increase when patches were represented by a dominance of Calluna (PPE 4.7).

However, other simulations have shown that variation in PPEs is not the major cause to changes in RSAP. Using the simulation approach, Sugita (1994) and Sugita et al. (1999) have shown that the RSAP is affected by the patterning of vegetation within the landscape, by taxon-specific properties of the pollen grains, and by the size of the basin from which the pollen assemblages are extracted. Sugita et al. (1999) also showed that the number of taxa included in the landscape did not have a significant effect on the RSAP. Bunting et al. (2004) further explored the effect on RSAP of varying taxon parameters and landscape patterning, using very simple scenarios composed of tree species only. The simulations suggested that, for basins of given sizes, and under fixed atmospheric conditions, the RSAP is primarily an expression of patterning of the different vegetation elements in the landscape. RSAP was largely independent of the fall speed or relative pollen productivity of the taxa present in the landscape, which means that the species involved have a secondary effect on RSAP, at least where only tree taxa are involved.

In order to test the effect on RSAP of varying patch size in a mixture of arboreal and herbaceous communities, Broström et al. (2005) used (1) empirical data extracted from vegetation inventories in the field and the interpretation of air photos, (2) simulated, simplistic landscapes mimicking the mosaic open and half-open landscapes of southern Sweden, and (3) vegetation maps. These experiments also demonstrated a very significant effect of the vegetation patterning on the RSAP. Sugita et al. (1999) argued that the large differences in RSAP estimates in the cultural landscapes of southern Sweden and in the closed forests of northern Michigan were mostly caused by differences in the distribution of the vegetation patches in the landscapes. Bunting et al. (2004) tested the effect of rarity on RSAP in forested landscapes by varying the proportion of a single taxon (Betula). In this experiment, RSAP was highest when the composition of taxa was more or less even, and decreased with increasing Betula dominance or rarity. New simulations were performed recently to further test the effects of variations in evenness and community diversity on RSAP (Hellman et al. 2008c, in press). It was shown that a decrease in landscape evenness, i.e. an increase in dominance of one taxon when all other taxa are randomly distributed in the landscape, will often result in an increase of the RSAP estimates, as will increases in the total number of taxa included in the landscape. The authors proposed that landscape structure is the major influencing factor on the RSAP, i.e. the spatial distribution of the taxa/ patches in the landscape as suggested by Sugita et al. (1999).

The importance of PPEs and background pollen

A common feature which emerges from the examples presented in this paper is the importance of PPE values for estimates of pollen loadings. In example 5 above, the use of two different PPEs for Calluna makes a significant difference to the results. In example 6, the results may indicate that the PPEs from southern Sweden are not applicable in northern Sweden. This means that there is a need for PPEs to be calculated for the same species in different geographical and ecological situations (Broström et al. 2008, this volume). Consistently patch size and the structure of the vegetation also stand out as factors which influence the output of the model in terms of pollen loadings, far more than wind speed or species composition within the vegetation units. Wind speed plays an observable role but the magnitude of this is not as great as the effect of PPEs and/or patch size.

Background pollen plays a much larger role than has previously been assumed. Background pollen is coming from outside of the RSAP; admittedly this may be 'extra local' or 'regional' in the more conventionally used terminology (Jacobson and Bradshaw 1981) and have its origin closer to the site of pollen loading than the conventionally envisaged 'long distance transported pollen'. Thus, the extent to which background pollen can dominate the pollen loading must always be taken into account.

Detection of small vegetation patches in a landscape

The simulation results in example 4 should be interpreted with caution in terms of absolute numbers. The model 
treats the trees as pollen sources at ground level, which explains pollen percentages of already less than $1 \% 2 \mathrm{~m}$ away from the Picea stand. A change in wind speed can influence the outcome of simulations as is shown in Nielsen (2003) and Eklöf et al. (2004). Increasing the wind speed would result in reduced Picea pollen percentages for sampling points inside the Picea stands, and higher percentages further away from the stands. The slope of the curves in Fig. 8 would become gentler with a larger scatter and the lowest values would be somewhat higher. Moreover, because the PPEs used are from southern Sweden, this might affect Picea more than Betula and Pinus, since the flowering cycles of Picea are comparably longer in the north of Sweden (see Broström et al. 2008, this volume for PPEs in Central Sweden). Lower PPEs would reduce the Picea scores on all sampling points regardless of their distance to the closest stand.

Under the assumptions of the model, and despite the uncertainties mentioned above, the simulations predict that it might be difficult to detect small tree populations in a high pollen-producing landscape. High pollen counts and a careful examination of very small pollen percentages are necessary. A scenario with very small stands or single trees evenly distributed in the landscape has the best chance of detection, whilst the pollen representation of rare patches of Picea depends greatly on the distance from the sampling point to the Picea stand as well as on local wind speeds and directions.

Quantitative reconstructions of past vegetation and landscape

The preliminary results from Ireland and Norway (example 5) demonstrate that the simulation approach offers an opportunity not just to try to reconstruct what the past was like, but perhaps more importantly to refute hypothesized past landscape structures. There will always be a problem of equifinality, leading to a range of landscapes providing the same fossil result, but in collaboration with archaeologists, palaeoecologists can now test and if necessary, reject or confirm ideas on openness, scale of clearance and cultural mosaics, themes that have been the subject of intense debate for many decades. With improved data for pollen productivity in different areas, the approach will provide new possibilities for the understanding of human impact and the development of the cultural landscape through time (see also Caseldine and Fyfe 2006; Caseldine et al. 2007a, b, this volume). The MSA (Bunting et al. 2007, 2008) is a sophisticated development of the approach used in this paper, taking advantage of the GIS technique. It is a promising tool for mapping past vegetation and landscapes at the local spatial scale (Bunting et al. 2007; Karlsson 2008). The MSA does not require using LRA estimates of vegetation abundance (e.g. Karlsson 2008). However, the MSA and LRA have the potential to be combined in the future. They represent-each approach alone or the two approaches combined-the soundest tools to date for quantitative reconstructions of past vegetation inferred from pollen records. Building on the theoretical understanding of the factors and mechanisms that affect pollen representation of vegetation, the LRA is able to estimate both regional and local abundance of plant species using fossil pollen assemblages in percentages. The basic assumptions for the LRA are similar to those listed for the Prentice-Sugita model (Sugita 1994; see theoretical background above). Among the parameters used in the LRA approach, PPE is one of the most important. The models included in the LRA assume that pollen productivity is constant through time. Even though the effects of climate change (Hicks 2001; Broström et al. 2008, this volume), and changes in species composition, grazing pressure, and land use (e.g. Hjelle 1998; Broström 2002; Mazier 2006; Mazier et al. 2008, this volume) might influence pollen productivity, the assumption is a valid first approximation in a given region and for periods characterized by moderate climate changes in a long term perspective, e.g. Middle and Late Holocene (Broström et al. 2008, this volume). Some may suggest that the simulation approach (using POLLSCAPE or HUMPOL), the LRA, and the MSA are flawed because of the assumption of constant pollen productivity through time. Together with Sugita $(2007 \mathrm{a}, \mathrm{b})$ we argue that, on the contrary, one of the advantages of using a model-based approach to vegetation reconstruction is that assumptions are clearly stated. Thanks to this clarity, the potentials and limitations of quantitative reconstruction of vegetation can be objectively evaluated.

Acknowledgments We are very grateful to NordForsk for sponsoring the POLLANDCAL network, allowing us to develop our ideas on quantitative reconstructions of vegetation over 5 years. We also thank all colleagues outside POLLANDCAL for their interest in our work, and for involving us in research activities in which the POLLANDCAL approach could be helpful. In that respect, we especially thank Frank Oldfield (former leader of the IGBP PAGES Programme) and John Dearing [former leader of the HITE (Human Impacts on Terrestrial Ecosystems) working group of IGBP PAGES Focus 5], presently leader of Focus 4 "Past Human-Climate-Ecological Interactions (PHAROS). We are grateful for the very useful comments and suggestions of two anonymous reviewers.

\section{Appendix}

List of the POLLANDCAL members with their addresses (Table 11). 
Table 11 POLLANDCAL members list (10/06/08) compiled by Michael Grant and updated by M.-J. Gaillard

\begin{tabular}{|c|c|c|}
\hline \multicolumn{3}{|l|}{ Senior researchers/lecturers } \\
\hline Andy Lotter & University of Utrecht, Netherlands & A.F.Lotter@uu.nl \\
\hline Anneli Poska & TTU, Estonia & Poska@gi.ee \\
\hline Antti Huusko & University of Oulu, Finland & Antti.Huusko@oulu.fi \\
\hline Barbora Lučeničová & Masaryk University, Czech Republic & barbora@ecb.cz \\
\hline Bent Odgaard & Aarhus University, Denmark & bent.odgaard@geo.au.dk \\
\hline Chris Caseldine & University of Exeter, UK & C.J.Caseldine@exeter.ac.uk \\
\hline Henna Suutari & University of Oulu, Finland & henna.suutari@oulu.fi \\
\hline Jacques-Louis de Beaulieu & University of Marseille, France & Jacques-Louis.de-Beaulieu@univ.u-3mrs.fr \\
\hline Jane Bunting & University of Hull, UK & M.bunting@hull.ac.uk \\
\hline Kari Hjelle & University of Bergen, Norway & Kari.Hjelle@bm.uib.no \\
\hline Lucia Wick & University of Basel, Switzerland & Lucia.Wick@unibas.ch \\
\hline Małgorzata Latałowa & University of Gdansk, Poland & bioml@univ.gda.pl \\
\hline Margrét Hallsdóttir & Institute of Natural History, Reykjavik, Iceland & mh@ni.is \\
\hline Marie-José Gaillard & Kalmar University, Sweden & marie-jose.gaillard-lemdahl@hik.se \\
\hline Mary Edwards & University of Southampton & M.E.Edwards@Soton.ac.uk \\
\hline Mihkel Kangur & Tallinn University, Estonia & mihkel.kangur@tlu.ee \\
\hline Petri Pellikka & University of Helsinki, Finland & Petri.Pellikka@helsinki.fi \\
\hline Petter Pilesjö & Lund University, Sweden & petter.pilesjo@natgeo.lu.se \\
\hline Ralph Fyfe & University of Plymouth, UK & ralph.fyfe@plymouth.ac.uk \\
\hline Richard Middleton & University of Hull, UK & r.middleton@hull.ac.uk \\
\hline Sheila Hicks & University of Oulu, Finland & Sheila.Hicks@oulu.fi \\
\hline Shinya Sugita & University of Tallinn, Estonia & sugita@umn.edu \\
\hline Siim Veski & Tallinn Technical University, Estonia & Veski@gi.ee \\
\hline Tiiu Koff & Tallinn University, Estonia & tiiu.koff@tlu.ee \\
\hline \multicolumn{3}{|c|}{ Post-docs/research assistant/other } \\
\hline Anna Broström ${ }^{a}$ & Lund University, Sweden & anna.brostrom@geol.lu.se \\
\hline Anne Birgitte Nielsen ${ }^{a}$ & GEUS, Denmark & abn@geus.dk \\
\hline Anne Bjune ${ }^{a}$ & NFR, Norway & anne.bjune@bio.uib.no \\
\hline Florence Mazier $^{\mathrm{a}}$ & University of Besançon, France & florence.mazier@univ-fcomte.fr \\
\hline Heather Binney & University of Southampton, UK & H.A.Binney@Soton.ac.uk \\
\hline Helen Shaw ${ }^{\mathrm{a}}$ & University of Cumbria, UK & helen@theuplandcentre.org.uk \\
\hline Henrik von Stedingk $^{\mathrm{a}}$ & SLU, Sweden & Henrik.von.Stedingk@svek.slu.se \\
\hline Kristina Duffin ${ }^{a}$ & Oxford University, UK & kristina.duffin@ouce.ox.ac.uk \\
\hline Michael Grant ${ }^{\mathrm{a}}$ & Wessex Archaeology Ltd, Salisbury, UK & m.grant@wessexarch.co.uk \\
\hline Mona Court-Picon ${ }^{\mathrm{a}}$ & Europole Méditerranéen de l'Arbois, France & mona.court-picon@univ.u-3mrs.fr \\
\hline Naoko Sasaki ${ }^{\mathrm{a}}$ & Research Institute for Humanity and Nature, Japan & naonao@kais.kyoto-u.ac.jp \\
\hline Naomi Holmes & University of Exeter, UK & n.holmes@exeter.ac.uk \\
\hline Per Sjögren $^{\mathrm{a}}$ & University of Bern, Switzerland & per.sjoegren@ib.uit.no \\
\hline Sandra Pratt ${ }^{\mathrm{a}}$ & University of Edinburgh, UK & s0128873@sms.ed.ac.uk \\
\hline Satu Räsänen ${ }^{\mathrm{a}}$ & University of Oulu, Finland & satu.rasanen@oulu.fi \\
\hline Sonia Fontana ${ }^{a}$ & University of Liverpool, UK & Sonia.Fontana@liv.ac.uk \\
\hline Thomas Giesecke $^{\mathrm{a}}$ & University of Liverpool, UK & Thomas.Giesecke@liverpool.ac.uk \\
\hline Verushka Valsecchi & University of Utrecht, Netherlands & verushka.valsecchi@ips.unibe.ch \\
\hline Sophie Hellman ${ }^{\mathrm{a}}$ & Kalmar University, Sweden & sofie.hellman@hik.se \\
\hline Hanna Karlsson $^{\mathrm{a}}$ & SLU, Sweden & Hanna.Karlsson@svek.slu.se \\
\hline Welmoed Soepboer $^{\mathrm{a}}$ & University of Utrecht, Netherlands & w.soepboer@bio.uu.nl \\
\hline \multicolumn{3}{|l|}{ Ph.D. and masters students } \\
\hline Annica Greisman & Kalmar University, Sweden & annica.greisman@hik.se \\
\hline Claire Twiddle & University of Exeter, UK & ct253@exeter.ac.uk \\
\hline
\end{tabular}


Table 11 continued

\begin{tabular}{|c|c|c|}
\hline Edgar Sepp & TTU, Estonia & Edgar@ut.ee \\
\hline Gunnar Gustavsson & Kalmar University, Sweden & gunnar.gustavsson@skola.varberg.se \\
\hline Kalev Koppel & University of Tartu, Estonia & kalev.koppel@ra.ee \\
\hline Kirsi Valta-Hulkkonen & University of Oulu, Finland & kirsi.valta@oulu.fi \\
\hline Mari Hagberg & University of Oulu, Finland & mari.hagberg@oulu.fi \\
\hline Mari Kuoppamaa & University of Oulu, Finland & mari.kuoppamaa@oulu.fi \\
\hline Martina Hättestrand & Stockholm University, Sweden & martina.hattestrand@geo.su.se \\
\hline Michelle Farrell & University of Hull, UK & M.Farrell@2005.hull.ac.uk \\
\hline Pericles Nacionales & University of Minnesota, USA & pnaciona@umn.edu \\
\hline Vivika Meltsov & University of Tartu, Estonia & vivika@zbi.ee \\
\hline \multicolumn{3}{|c|}{ Researchers associated with the PolLandCal group (but not actively participating) } \\
\hline Alexandre Buttler & University of Besançon, France & alexandre.buttler@epfl.ch \\
\hline Ann-Marie Robertsson & Stockholm University, Sweden & ann-marie.robertsson@geo.su.se \\
\hline Brigitta Ammann & University of Bern, Switzerland & brigitta.ammann@ips.unibe.ch \\
\hline Cécile Brun & University of Besançon, France & Cecile.brun@univ-fcomte.fr \\
\hline Dominique Marguerie & University of Rennes, France & Dominique.marguerie@univ-rennes1.fr \\
\hline Greger Hörnberg & Umeå University, Sweden & greger.hornberg@emg.umu.se \\
\hline Hikaru Takahara & Kyoto Prefectural University & takahara@kpu.ac.jp \\
\hline Hilary Birks & University of Bergen, Norway & hilary.birks@bio.uib.no \\
\hline Jarno Mikkola & University of Oulu, Finland & jarno.mikkola@oulu.fi \\
\hline John Birks & University of Bergen, Norway & john.birks@bio.uib.no \\
\hline Karl-Dag Vorren & University of Troms $\emptyset$ & karl-dag.vorren@ib.uit.no \\
\hline Keith Bennett & Queen's University Belfast, UK & k.d.bennett@queens-belfast.ac.uk \\
\hline Markus Heinrichs & University of Munich, Germany & markus.heinrichs@wzw.tum.de \\
\hline Martyn Waller & Kingston University, UK & M.Waller@Kingston.ac.uk \\
\hline Olavi Heikkinen & University of Oulu, Finland & olavi.heikkinen@oulu.fi \\
\hline Per Lagerås & National Heritage Board, Sweden & per.lageras@raa.se \\
\hline Richard Bradshaw & University of Liverpool, UK & Richard.Bradshaw@liverpool.ac.uk \\
\hline Stefanie Jacomet & University of Basel, Switzerland & Stefanie.Jacomet@unibas.ch \\
\hline Ulf Segerström & SLU, Sweden & Ulf.Segerstrom@svek.slu.se \\
\hline
\end{tabular}

${ }^{a}$ Ph.D. students during part or all of 2001-2005

\section{References}

Andersen ST (1970) The relative pollen productivity and representation of north European trees, and correction factors for tree pollen spectra. Dan Geologiske Undersøgelse II 96:1-99

Andersen ST (1973) The differential pollen productivity of trees and its significance for the interpretation of pollen diagram from a forested region. In: Birks HJB, West RG (eds) Quaternary plant ecology. Blackwell, Oxford, pp 109-116

Anderson NJ, Bugmann H, Dearing JA, Gaillard M-J (2006) Linking palaeoenvironmental data and models to understand the past and to predict the future. Trends Ecol Evol 21:696-704

Bradshaw RHW, Webb TIII (1985) Relationship between contemporary pollen and vegetation data from Wisconsin and Michigan, USA. Ecology 66:721-737

Broström A (2002) Estimating source area of pollen and pollen productivity in cultural landscapes of southern Sweden-developing a palynological tool for quantifying past plant cover. Ph.D. thesis, Department of Quaternary Geology, Lund University, Lund

Broström A, Gaillard M-J, Ihse M, Odgaard B (1998) Pollenlandscape relationships in modern analogues of ancient cultural landscapes in southern Sweden-a first step towards quantification of vegetation openness in the past. Veget Hist Archaeobot 7:189-201

Broström A, Sugita S, Gaillard M-J (2004) Pollen productivity estimates for reconstruction of past vegetation cover in the cultural landscape of Southern Sweden. Holocene 14:371-384

Broström A, Sugita S, Gaillard M-J (2005) Estimating the spatial scale of pollen dispersal in the cultural landscape of southern Sweden. Holocene 15:252-262

Broström A, Nielsen B, Gaillard M-J, Hjelle K, Mazier F, Binney H, Bunting J, Fyfe R, Meltsov V, Poska A, Räsänen S, Soepboer W, von Stedingk H, Suutari H, Sugita S (2008) Pollen productivity estimates of key European plant taxa for quantitative reconstruction of past vegetation: a review. Veget Hist Archaeobot 17. doi:10.1007/s00334-008-0148-8

Bunting J, Middleton R (2005) Modelling pollen dispersal and deposition using HUMPOL software, including simulating windroses and irregular lakes. Rev Palaeobot Palynol 134:185196

Bunting J, Gaillard M-J, Sugita S, Middleton R, Broström A (2004) Vegetation structure and pollen source area. Holocene 14:651660 
Bunting MJ, Armitage R, Binney HA, Waller M (2005) Estimates of "relative pollen productivity" and "relevant source area of pollen" for major tree taxa in two Norfolk (UK) woodlands. Holocene 15:459-465

Bunting MJ, Middleton R, Twiddle CL (2007) Wetland records of a coastal cultural landscape in north-west Scotland: an application of the multiple scenario approach to landscape reconstruction. In: Barber B, Clark C, Cressey M, Crone A, Hale A, Henderson J, Housley R, Sands R, Sheridan A (eds) Archaeology from the Wetlands: recent perspectives (WARP Occasional Paper 18). Society of Antiquaries of Scotland, Edinburgh, pp 109-117

Bunting MJ, Twiddle CL, Middleton R (2008) Reconstructing past vegetation in mountain areas from pollen data: application of models of pollen dispersal and deposition. Palaeogeogr Palaeoclim Palaeoecol 259:77-91

Calcote R (1995) Pollen source area and pollen productivity: evidence from forest hollows. J Ecol 83:591-602

Caseldine C, Fyfe R (2006) A modelling approach to locating and characterising elm decline/landnam landscapes. Quatern Sci Rev 25:632-644

Caseldine C, Fyfe R, Langdon C, Thompson G (2007a) Simulating the nature of vegetation communities at the opening of the Neolithic on Achill Island, Co. Mayo, Ireland - the potential role of models of pollen dispersal and deposition. Rev Palaeobot Palynol 144:135-144

Caseldine C, Fyfe R, Hjelle K (2007b) Pollen modelling, palaeoecology and archaeology-virtualisation and/or visualisation of the past? Veget Hist Archaeobot 17. doi:10.1007/s00334-0070093-y

Davis MB (1963) On the theory of pollen analysis. Am J Sci 261:897-912

Davis MB (1966) Determination of absolute pollen frequency. Ecology 47:310-311

Davis MB (1968) Pollen grains in lake sediments: redeposition caused by seasonal water circulation. Science 162:769-799

Davis MB (2000) Palynology after Y2K-understanding the source area of pollen in sediments. Ann Rev Earth Plan Sci 28:1-18

Davis MB, Brubacker LB (1973) Differential sedimentation of pollen grains in lakes. Limnol Oceanogr 18:635-646

Davis MB, Sugita S (1996) Reinterpreting the fossil pollen record of Holocene tree migration. In: Huntley B, Cramer W, Morgan AV, Prentice IC, Allen IRM (eds) Past and future rapid environment change: the spatial and evolutionary responses of terrestrial biota. Springer, Berlin, pp 181-193

Davis MB, Brubaker LB, Webb TIII (1973) Calibration of absolute pollen influx. In: Birks HJB, West RG (eds) Quaternary plant ecology. Blackwell, Oxford, pp 9-25

Davis MB, Moeller RE, Ford J (1984) Sediment focusing and pollen influx. In: Haworth Y, Lund JWG (eds) Lake sediments and environmental history. University of Leicester Press, Leicester, pp 261-293

Edwards AWF (1972) Likelihood: an account of the statistical concept of likelihood and its application to scientific inference. Cambridge University Press, London

Eisenhut G (1961) Untersuchungen über die Morphologie und Ökologie der Pollenkörner heimischer und fremdländischer Waldbäume (translated into English by Jackson ST, Jaumann P 1989). Parey, HamburgS

Eklöf M, Broström A, Gaillard M-J, Pilesjö P (2004) OPENLAND3: a computer program to estimate plant abundance around pollen sampling sites from vegetation maps: a necessary step for calculation of pollen productivity estimates. Rev Palaeobot Palynol 132:67-77

Fagerlind F (1952) The real significance of pollen diagrams. Bot Notiser 105:185-224
Fyfe R (2006) GIS and the application of a model of pollen deposition and dispersal: a new approach to testing landscape hypotheses using the POLLANDCAL models. J Archaeol Sci 33:483-493

Gaillard M-J (1985) Late-Glacial and Holocene environments of some ancient lakes in the western Swiss Plateau. In: Lang G (ed) Swiss lake and mire environments during the last 15000 years, vol 87. Diss Bot, pp 273-336

Gaillard M-J (2007) Pollen methods and studies-archaeological applications. In: Elias SA (ed) Encyclopedia of quaternary science, vol 3. Elsevier, Amsterdam, pp 2575-2595

Gaillard M-J, Lemdahl G (1994) Lateglacial insect assemblages from Grand-Marais, south-western Switzerland-climatic implications and comparison with pollen and plant macrofossil data. In: Lotter AF, Ammann B (eds) Festschrift Gerhard Lang, vol 234. Diss Bot, pp 287-308

Gaillard M-J, Sugita S, Broström A, Eklöf M (2000) Long term landcover changes on regional to global scales inferred from fossil pollen-how to meet the challenges of climate research? PAGES Newsl 3:30-32

Giesecke T (2005) Holocene forest development in the central Scandes Mountains, Sweden. Veget Hist Archaeobot 14:133147

Gregory PH (1973) The microbiology of the atmosphere. Leonard Hill, Aylesbury, p 377

Hellman S (2007) Validating and Testing the Landscape Reconstruction Algorithm in Southern Sweden-Towards Quantitative Reconstruction of Past Vegetation. Dissertation, University of Kalmar, Dissertation series 46

Hellman S, Gaillard M-J, Broström A, Sugita S (2008a) The REVEALS model, a new tool to estimate past regional plant abundance from data in large lakes: validation in southern Sweden. J Quat Sci 23:21-42

Hellman SEV, Gaillard M-J, Broström A, Sugita S (2008b) Effects of the sampling design and selection of parameter values on pollenbased quantitative reconstructions of regional vegetation: a case study in southern Sweden using the REVEALS model. Veget Hist Archaeobot 17. doi:10.1007/s00334-008-0149-7

Hellman S, Gaillard M-J, Bunting MJ (2008c) Pollen dispersal and deposition in patchy cultural landscapes: modelling relevant source area of pollen and signals of anthropogenic landscape disturbance in the pollen record. Rev Palaeobot Palynol (in press)

Hellman S, Gaillard M-J, Bunting MJ (2008d) Relevant source area of pollen in cultural landscapes-a simulation approach. Rev Palaeobot Palynol (in press)

Hicks S (2001) The use of annual arboreal pollen deposition values for delimiting treelines in the landscape and exploring models of pollen dispersal. Rev Palaeobot Palynol 117:1-29

Hicks S, Hyvärinen H (1999) Pollen influx values measured in different sedimentary environments and their palaeoecological implications. Grana 38:228-242

Hjelle KL (1998) Herb pollen representation in surface moss samples from mown meadows and pastures in western Norway. Veget Hist Archaeobot 7:79-96

Huntley B, Birks HJB (1983) An atlas of past and present pollen maps for Europe 0-13 000 years ago. Cambridge University Press, Cambridge

Iversen J (1944) Viscum, Hedera and Ilex as climate indicators. GFF 66:774-776

Iversen J (1964) Plant indicators of climate, soil and other factors during the Quaternary. In: Proceeding INQUA 1961, Moscow, pp 421-428

Jackson ST (1990) Pollen source area and representation in small lakes of the northeastern United States. Rev Palaeobot Palynol 63:53-56 
Jackson ST (1994) Pollen and spores in quaternary lake sediments as sensors of vegetation composition: theoretical models and empirical evidence. In: Traverse A (ed) Sedimentation of organic particles. Cambridge University Press, Cambridge, pp 253-286

Jackson ST, Kearsley JB (1998) Quantitative representation of local forest composition in forest-floor pollen assemblages. $\mathrm{J}$ Ecol 86:474-490

Jackson ST, Lyford ME (1999) Pollen dispersal models in quaternary plant ecology: assumptions, parameters, and prescriptions. Bot Rev 65:39-75

Jacobson GL, Bradshaw RHW (1981) The selection of sites for paleovegetational studies. Quatern Res 16:80-96

Karlsson H (2008) Vegetation changes and forest-line positions in the Swedish Scandes during late Holocene-Anthropogenic impact vs. climate, vol 31. Doctoral Thesis, Umeå. Acta Universitatis agriculturae Sueciae

Kullman L (1996) Norway spruce present in the Scandes Mountains, Sweden at 8000 BP: new light on Holocene tree spread. Glob Ecol Biogeogr Lett 5:94-101

Mazier F (2006) Modelling modern pollen assemblages, vegetation and pastoral activities in middle range mountains (Pyrenees and Jura). Applications for the interpretation of fossil pollen records (Synthesis in French, four papers in English). Thesis, Neuchâtel and Franche Comté Universities

Mazier F, Brostöm A, Gaillard M-J, Sugita S, Vittoz P, Buttler A (2008) Pollen productivity estimates and Relevant Source Area for major taxa in a pasture woodland (Jura mountains, Switzerland). Veget Hist Arch 17. doi:10.1007/s00334-008-0143-0

Middleton R, Bunting MJ (2004) Mosaic v1.1: landscape scenario creation software for simulation of pollen dispersal and deposition. Rev Palaoeobot Palynol 132:61-66

Nielsen AB (2003) Pollen based quantitative estimation of land cover-relationships between pollen sedimentation in lakes and land cover as seen on historical maps in Denmark AD 1800. $\mathrm{Ph} . \mathrm{D}$. thesis, University of Copenhagen, and Geological Survey of Denmark and Greenland. Danmarks og Grønlands geologiske unders $\varnothing$ gelse rapport 2003/57

Nielsen AB (2004) Modelling pollen sedimentation in Danish lakes at c. AD 1800: an attempt to validate the POLLSCAPE model. J Biogeogr 31:1693-1709

Nielsen AB, Sugita S (2005) Estimating relevant source area of pollen for small Danish lakes around AD 1800. Holocene 15:10061020

Parsons RW, Prentice IC (1981) Statistical approaches to R-values and the pollen-vegetation relationship. Rev Palaeobot Palynol 32:127-152

Prentice IC (1985) Pollen representation, source area, and basin size: toward a unified theory of pollen analysis. Quatern Res 23:76-86

Prentice IC (1988) Records of vegetation in time and space: the principles of pollen analysis. In: Huntley B, Webb TIII (eds) Vegetation history. Kluwer, Dordrecht, pp 17-42

Prentice IC, Parsons RW (1983) Maximum likelihood linear calibration of pollen spectra in terms of forest composition. Biometrics 39:1051-1057

Prentice IC, Webb TIII (1986) Pollen percentages, tree abundances and the Fagerlind effect. J Quat Sci 1:35-43

Prentice IC, Berglund BE, Olsson T (1987) Quantitative forestcomposition sensing characteristics of pollen samples from Swedish lakes. Boreas 16:43-54

Schwarz MW (1989) Predicting tree frequencies from pollen frequency: an attempt to validate the $\mathrm{R}$ value method. New Phytol 112:129-143
Segerström U, von Stedingk H (2003) Early Holocene spruce (Picea abies (L.) Karst) in west central Sweden as revealed by pollen analysis. Holocene 13:897-906

Snowball I, Zillen L, Gaillard MJ (2001) Rapid early Holocene environmental changes in northern Sweden based on studies of two varved lake sediments sequences. Holocene 12:7-16

Soepboer W, Sugita S, Lotter A, van Leuwen JFN, van der Knaap WO (2007a) Pollen productivity estimates for quantitative reconstruction of vegetation cover on the Swiss Plateau. Holocene 17:1-13

Soepboer W, Vervoort JM, Sugita S, Lotter AF (2007b) Evaluating Swiss pollen productivity estimates using a simulation approach. Veget Hist Archaeobot 17. doi:10.1007/s00334-007-0128-4

Soepboer W, Sugita S, Lotter A (2008) Modelling regional vegetation changes on the Swiss Plateau during the past two millennia. Quat Sci Rev (in press)

Sugita S (1993) A model of pollen source area for an entire lake surface. Quatern Res 39:239-244

Sugita S (1994) Pollen representation of vegetation in quaternary sediments: theory and method in patchy vegetation. J Ecol $82: 881-897$

Sugita S (1998) Modelling pollen representation of vegetation. In: Gaillard MJ, Berglund BE, Frenzel B, Huckriede U (eds) Quantification of land surfaces cleared of forests during the Holocene, vol 27. Palaeoclimate Research, Fischer, Stuttgart, pp $1-15$

Sugita S (2007a) Theory of quantitative reconstruction of vegetation. I. Pollen from large sites REVEALS regional vegetation. Holocene 17:229-241

Sugita S (2007b) Theory of quantitative reconstruction of vegetation. II. All you need is LOVE. Holocene 17:243-257

Sugita S (2007c) POLLSCAPE model. In: Elias SA (ed) Encyclopedia of quaternary science. Elsevier, Amsterdam, pp 25612570

Sugita S, MacDonald GM, Larsen CPS (1997) Reconstruction of fire disturbance and forest succession from fossil pollen in lake sediments: potential and limitations. In: Clark JS, Cachier H, Goldmmer JG, Stocks BJ (eds) Sediment records of biomass burning and global change. Springer, Berlin, pp 387-412

Sugita S, Gaillard M-J, Broström A (1999) Landscape openness and pollen records: a simulation approach. Holocene 9:409-421

Sugita S, Gaillard M-J, Hellman S, Broström A (2008) Model-based reconstruction of vegetation and landscape using fossil pollen. In: Proceedings of the 35th CAA (computer applications and quantitative methods in archaeology) conference, Berlin, April 2007 (in press)

Sutton OG (1953) Micrometeorology. McGraw-Hill, New York

Tauber H (1965) Differential pollen dispersal and the interpretation of pollen diagrams, vol 89. Danmarks Geologiske Undersøgelse (Afhandlinger), Række II, pp 1-69

von Stedingk H (2006) History of Picea abies in west central Sweden-applications of pollen analysis to reveal past local presence of trees. Doctoral Diss, Dept. of Forest Vegetation Ecology, SLU

von Stedingk H, Fyfe R, Allard A (2008) Pollen productivity estimates for the reconstruction of past vegetation at the foresttundra ecotone. Holocene (in press)

Webb TIII, Howe SE, Bradshaw RHW, Heide KM (1981) Estimating plant abundances from pollen percentages - the use of regression analysis. Rev Palaeobot Palynol 34:269-300 